150 YEARS OF THE

BRITISH MEDICAL ASSOCIATION

\title{
Annual Report of Council 1981-1982
}




\section{Message from the Chairman of Council}

When Charles Hastings gathered with his colleagues in the board room at Worcester Royal Infirmary on 19 July 1832 to found the Provincial Medical and Surgical Association, could he have possibly foreseen the significance of the occasion? Even a man of his great vision could never have guessed that 150 years later a royal prince, HRH The Prince of Wales, would, like his father before him, become President of an internationally recognised Association founded originally to fulfil the professional needs of the country's provincial doctors.

Since 1832 the Association has striven to maintain the honour and interests of the medical profession and can now claim a pre-eminent place in the affairs of our profession, of the nation, and among medical associations worldwide.

Our Association has been blessed with many distinguished Presidents, and it is a particular pleasure to record the thanks of Council to the present incumbent-Sir John Walton. His two-year period of office has been an outstanding success and his recent election to the presidency of the General Medical Council will give great pleasure to all members of the Association.

This year, like many before it, has brought difficult problems for the profession but the Council and the major committees have been working strenuously to resolve them. Their efforts on your behalf are recorded in this report but I would like to highlight some of the most important issues.

The session has been notable for a wide-ranging debate on the problems of medical manpower in general and of the hospital staffing structure in particular. Michael Rees and the Hospital Junior Staff Committee have kept the issues before the profession and have vigorously urged the Government, and all other parties concerned, to recognise the problems of young doctors' career prospects and long working hours and to find some solutions.

I am sure that, with common sense and good will, the profession can, and must, find a workable career structure acceptable to all branches of the profession. What concerns me more, however, is the increasing prospect of medical unemployment; this grave issue will, I believe, dominate medicopolitics during the forthcoming year. It will be a national disgrace if doctors appear in the dole queues and the BMA will do all in its power to see that this does not happen.

The future of the well established Review Body system for assessing doctors' remuneration has been threatened by the Government's policy on pay restraint in the public sector. There is little doubt, however, that most doctors prefer the independent review body system to the alternative of direct negotiations with the Government, with their risk of regular confrontations. Repeated failure by any government to implement the Review Body awards, or any interference with its independence, would seriously jeopardise a system which has been of great value both to the National Health Service and to the profession.

Reorganisation of the NHS has been proceeding apace and the General Medical Services Committee achieved a substantial political victory when it ensured that family practitioner committees would remain independent in the reorganised NHS. This success reflects great credit on John Ball and his committee. Equally important was the battle won by the Central Committee for Hospital Medical Services on the siting of consultants' contracts. Most of these are to stay with regional health authorities after reorganisation, a decision which is of fundamental importance to the future of consultants; all hospital doctors should thank David Bolt and his team for their successful efforts. For the second time in a decade doctors in community medicine have suffered career disturbances because of reorganisation, and the Central Committee for Community Medicine has fought hard in the interests of its constituents, but has had to face the harsh reality of redundancies within its specialty.

The Medical Academic Staff Committee, too, has been confronted by the alarming prospect of redundancies among its constituents. The cuts imposed by the Government on university spending were severe and sudden, and the committee has responded vigorously to minimise the damage to medical teachers, standards of medical education, and the future of medicine. Doctors cannot, of course, shut their eyes to the country's economic problems but the Council will continue to do its utmost to protect the interests of doctors and of the Health Service.

The BMA is proud of its record in ethics and in medicolegal matters and this year it has been called on to examine some difficult dilemmas facing the profession in these areas. In particular, the trial of Dr Leonard Arthur and the public debate on in-vitro fertilisation prompt anxieties which deserve careful consideration in and outside the profession. Society as a whole must discuss and advise on these fundamental issues: ultimately, however, individual doctors have to deal with them in the heat of daily practice, and I believe, therefore, that it is our responsibility to debate the arguments with particular care. While doing this we will be guided by the Central Ethical Committee, but it is imperative that all doctors join in the debate.

The year has produced challenges that would have startled our founding fathers but the BMA's growing membership, its attention to the needs of members throughout the country, and its increasing authority among doctors and the public would, I am sure, have pleased them well. I urge members to read this report carefully; it tells you what our Association has done for you. I am confident that when you have read it you will share my optimism for the future of the British Medical Association. 


\section{Contents}

Annual meetings and craft conferences 4

Armed Forces 12

Awards and honours 5

BMA deputising services 22

“BMA News Review” 17

"British Medical Journal" 17

Charities 18

Commonwealth and International Medical Advisory

Bureau 21

Commonwealth Medical Association 21

Community medicine 10

Doctors and social work 22

European Economic Community 20

Family Doctor Publications 17

Finances of the Association 17

General Medical Council 19

General practice 9

Junior hospital staff 9

Managerial, Professional, and Staff Liaison Group 22

Manpower 15

Medical academic staff 10

Medical ethics 14

Membership and regional services 18

NHS reorganisation 5

Northern Ireland 16

Occupational health 11

Ophthalmic medical services 12

Organisation 18

Personal Services Bureau 18

Preliminary 3

Private practice 13

Remuneration-Review Body 6

Scientific activities 6

Scotland 15

Senior hospital staff 8

Superannuation 12

Wales 16

World Medical Association 21

Appendix I-Council attendances 22

Appendix II-Advertising and the medical profession 23

Appendix III-BMA's response to the Fourth Report of the Social Services Committee on Medical Education 24

Appendix IV-Financial statement: balance sheet and income and expenditure account 26

Appendix V-Budget for 198230

Appendix VI-Amendments to the Articles, Bylaws, and Schedules to the Bylaws 32

\section{Preliminary}

(1.1) 1982 is the 150th Anniversary of the founding of the Association by Sir Charles Hastings and the anniversary is being commemorated by two meetings, details of which are given below.

(1.2) Since its foundation the Association has evolved from small provincial beginnings to a nationwide organisation which can justly claim to represent the very wide cross section of interests of doctors not only in their professional work but also in their trade union activities. The recent increase in membership to nearly two-thirds of the total number of practising doctors is a considerable achievement.

(1.3) One of the developments which the Council has been particularly pleased to welcome is the increasing interest shown in the work of the Association by medical students and junior doctors. The Hospital Junior Staff Committee has this session been particularly concerned with the problem of medical manpower, a subject which was given detailed consideration in the Fourth Report of the House of Commons Social Services Committee (Short Report) on Medical Education.

(1.4) All medical students are now eligible to become associate members of the Association and the continuing increase in their number is a source of great encouragement to the Council. Last year there were over 6000 , an increase of nearly 1000 over the previous year, and links are being strengthened with all the medical schools by regular visits from the Association's staff.

(1.5) The study of alternative methods of financing the NHS which the Council was asked to undertake by the Representative Body has now been completed. A report of the study is being sent to divisions as a discussion document, but any member of the Association who would like to receive a copy may apply to the Secretary.

(1.6) The Council is continuing to advise on the reorganisation of the NHS and is particularly concerned that doctors should be in a position to influence the management of the Service. In the present financial climate the NHS is unlikely to receive any substantial financial increase in real terms from public sources so that it will be essential for doctors to play a leading part in local decisions on the allocation of available resources.

(1.7) The outlook for academic medicine is a matter of considerable concern at the present time in the light of the severe cuts in grants to universities announced by the University Grants Committee last year. The Council has warned the Committee of Vice-chancellors and Principals and the Department of Education and Science that not only will the quality of medical education in this country be seriously affected by a cutback of medical teachers, but that adverse repercussions upon the NHS are likely since many patients are cared for directly or indirectly by medical academic staff in teaching hospitals.

(1.8) The statistical and economic support necessary for the standing committees and negotiating teams of the Association continues to be provided by the Economic Research Unit. The major task of this unit is the preparation of evidence to the Review Body on Doctors' and Dentists' Remuneration

Members are asked to keep this issue until the matters it contains have been discussed by their divisions. 
(DDRB) and this year the unit has been particularly engaged in advising on the evidence to be submitted to the DDRB on the evaluation of the work and responsibility of clinical members of district management teams. The unit also provided much of the information upon which the Council's study of alternative methods of financing the NHS was based.

(1.9) The Association's Legal Department continues to provide expert legal advice on a wide range of subjects not only to the Association's committees, but also to the central secretariat and to the Association's regional staff. This latter aspect of its role is particularly important as it is enabling the Association, through its regional staff, to strengthen the support and advice that are available to individual members.

(1.10) A summary of some of the highlights of the Council's year would not be complete without special mention of the work undertaken by BMA publications and by the Press Information Department. It is essential for the BMA to get its views across to the profession, to Parliament, and to the public. The British Medical fournal provides not only expert scientific comment on the wide range of subjects but also accurate reporting on all aspects of the Association's medicopolitical activities, a function which the Council believes no other medical journal can claim to fulfil. The Association's Press Information Department, together with a very active Professional Relations Unit and a Parliamentary Information Unit, are playing an increasing part in influencing public and Parliamentary opinion as well as keeping the profession's representatives fully informed.

(1.11) Membership of Council. The membership of Council for this session and a record of attendances at the four meetings held to date are set out in appendix I. A further meeting will take place at the beginning of May.

(1.12) The presence on Council of the following "Visitors to Council" was greatly appreciated this session: Dame Josephine Barnes, DBE, FRCP, FRCS, FRCOG; Sir Douglas Black, MD, PRCP; Mr R M Feroze, MD, FRCS, PRCOG; Dr J P Horder, OBE, MA, FRCP, PRCGP; and Sir Alan Parks, PRCS.

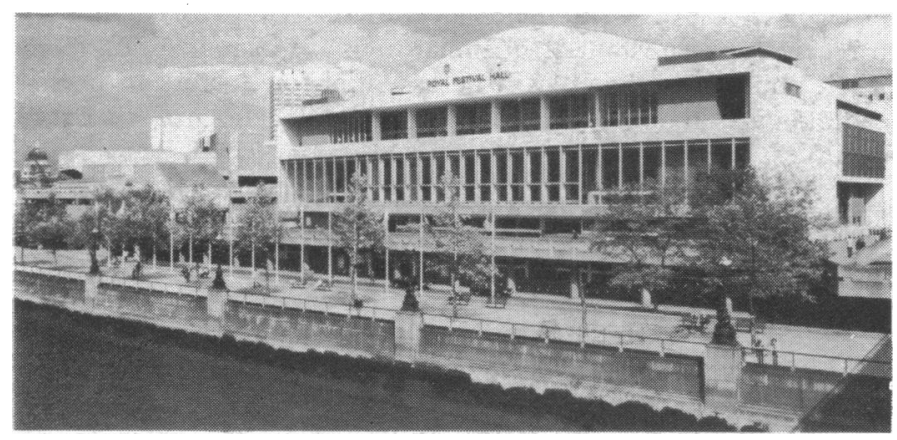

The Royal Festival Hall, where The Prince of Wales will be installed as President of the BMA on 7 July.

\section{President 1983-4}

(2.1) It is with great pleasure that the Council makes the following recommendation to the ARM 1982:

Recommendation: That Dr Ronald Foote Robertson, CBE, MD, FRCP, FRCPE, FRCPGlas, be elected President of the Association for 1983-4.

\section{Annual meetings and craft conferences}

(3.1) The 1982 Annual Representative Meeting will be held from 5 to 8 July at the Logan Hall, University of London's

\section{BMA President 1982-3}

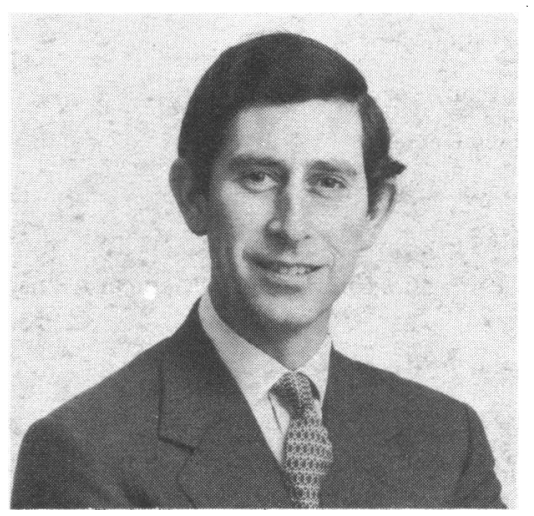

HRH The Prince of Wales, who will be installed as President of the BMA at the Adjourned Annual General Meeting.

Institute of Education. The Annual General Meeting of the Association will take place at $1250 \mathrm{pm}$ on Wednesday, 7 July in the Logan Hall.

(3.2) The Adjourned AGM will take place the same evening in the Royal Festival Hall, London, when HRH The Prince of Wales will be installed as President of the Association for 1982-3.

(3.3) The 1982 craft conferences will be held at BMA House, Tavistock Square, London WC1H 9JP, on:

\begin{tabular}{|c|c|}
\hline 14 June & $\begin{array}{l}\text { Conference of Medical Academic } \\
\text { Staff }\end{array}$ \\
\hline 17 June & Senior Hospital Stafis Conference \\
\hline 19 June & Hospital Junior Staff Conference \\
\hline 23 and 24 June & $\begin{array}{l}\text { Conference of Representatives of } \\
\text { Local Medical Committees }\end{array}$ \\
\hline 26 June & $\begin{array}{l}\text { Conference of Community } \\
\text { Medicine }\end{array}$ \\
\hline
\end{tabular}

(3.4) As part of its 150th anniversary celebrations the Association will be holding a major exhibition and symposium at Olympia, London, from 13 to 16 July 1982 within the International Hospital and Medical Exhibition. The theme of the symposium will be "Medicine in extreme conditions."

(3.5) The Hastings Celebration Meeting (scientific meeting) will take place in the Worcester College of Higher Education from 9 to 11 September 1982. The provisional programme was published in the $B M F$ on 9 January (p 134).

(3.6) In 1983 the ARM will be held in Dundee from 27 June to 1 July, and Manchester will be the venue for the 1984 ARM from 2 to 6 July. 
(3.7) The Annual Scientific Meeting in Cambridge which was originally planned for September 1983 will now take place from 12 to 14 April 1984.

(3.8) Overseas clinical meetings. The Association's first meeting in the USA-the San Diego Congress in October 1981 - attracted an attendance of 1300 doctors and their families from the UK and over 100 from overseas, the largest registration to date at an overseas clinical meeting. There was an audience of 1800, including many Californian doctors and their families, for the opening ceremony, which included Alistair Cooke's keynote address on "The Doctor in Society."

(3.9) The San Diego County Medical Society, which gave invaluable help with the organisation of the San Diego Congress, is planning a return visit to London and Edinburgh in April 1983.

(3.10) A further overseas clinical meeting is planned for the autumn of 1983 . The venue for the meeting has not yet been settled.

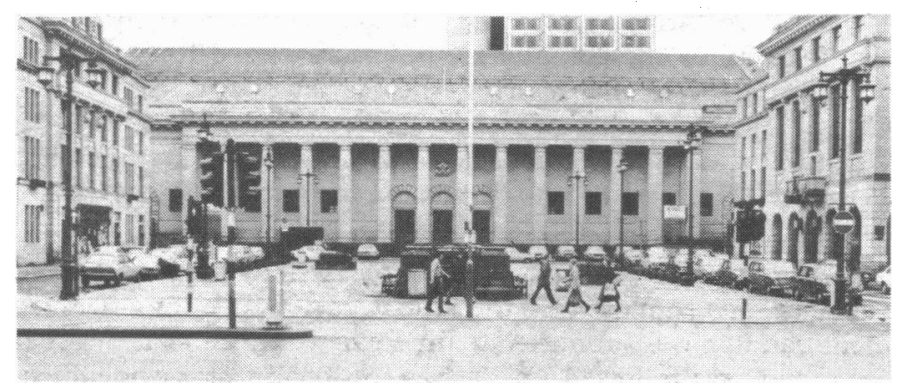

In 1983 the Annual Representative Meeting will be held in Dundee from 27 June to 1 July.

\section{Awards and honours}

(4.1) Gold Medal for Distinguished Merit. This high honour has been awarded by the Council to Dr Jack E Miller, JP, FRCGP, to the Rt Hon Lord Richardson, MVO, MD, FRCP, FRCPE, and to the Rt Hon Lord Smith of Marlow, KBE, MS, FRCS, in recognition of their outstanding services to the medical profession and to the Association. The medals will be formally presented by the President of the Association at the Adjourned AGM.

(5.1) Vice-presidents. The Council considers that recognition should be given to the outstanding services to the Association of Dr Alistair Clark and Dr Elston Grey-Turner.

Dr Clark was chairman of the Conference of Local Medical Committees from 1969 to 1972 and Chairman of the Representative Body from 1976 to 1979 . In addition, he was chairman of the Scottish General Medical Services Committee and has served on Council, the Scottish Council, the GMS Committee, and numerous other Association committees for many years. However, perhaps his greatest contribution to the Association was as chairman from 1976 to 1978 of the Working Party on the Functions and Priorities of the Association. It was the Representative Body's adoption of the working party's report which led to the development of the Association's peripheral services.

Dr Elston Grey-Turner retired as Secretary of the Association in 1979, having served the Association since 1948, when he was appointed assistant secretary. During the second world war he served in the RAMC, rose to the rank of lieutenantcolonel, and was awarded the Military Cross. He was a loyal servant of the Association for 31 years.

The Council has pleasure in recommending to the Representative Body:

Recommendation: That Dr A A Clark, $\mathrm{MB}, \mathrm{ChB}, \mathrm{JP}$, and Dr Elston Grey-Turner, CBE, MC, TD, MA, MRCS, LRCP, be elected vice-presidents of the Association in recognition of

their outstanding services to the Association and to the medical profession.

(6.1) Roll of Fellows. A highly successful dinner, attended by some 80 Fellows and their guests, was held at BMA House in October 1981. The chair was taken by the President of the Association, Sir John Walton. It is hoped to organise a similar function for Fellows in 1982. A special tie for Fellows has been designed and will shortly be on sale.

(6.2) The Council has been pleased to admit the following members to the Roll of Fellows:

Nominating division

Basingstoke and North Hampshire

Greenwich and Bexley

Halifax

Perth and Kinross

Renfrewshire

Shetland

Aldershot and Farnham

Leeds

East Hertfordshire

East Hertfordshire

Bradford and Airedale

(7.1) Certification of Commendation. The Council has been pleased to award the Certificate of Commendation to the following member:

\section{Nominating body Member}

South Glamorgan Division George Nutch Mitchell, MB, ChB. (three members)

\section{NHS reorganisation}

(8.1) Medical advisory machinery. In January the DHSS issued advice to health authorities on the arrangements for medical advisory machinery at district level. It was based on the report of the CMO's Working Group and it is left to the district health authority and the profession locally to decide whether to set up a district medical committee. Divisions were sent a copy of the circular and were reminded of the view of the ARM 1981 that there should be a district medical committee consisting of representatives of all branches of the profession, with the right, granted by statute, to give medical advice to and to be consulted by the DHA.

(8.2) The report of the CMO's Working Group on the advisory machinery at regional level was also issued in January and comments were invited by the Department by the end of March. The report has been circulated to divisions and craft committees. 


\section{Remuneration-Review Body}

(9.1) Implementation of the Eleventh Report. The Eleventh Report of the Review Body on Doctors' and Dentists' Remuneration (DDRB) was published on 15 May 1981. In the report the DDRB made recommendations for rates of remuneration for 1981-2 that were some $9 \%$ greater on average than the levels established in its Tenth Report, increases in the main falling within a range of $8.1 \%$ to $9.4 \%$. As is customary the Review Body made its recommendations to the Prime Minister. On this occasion the Prime Minister asked to meet the Chairman of Council and Secretary of the Association and told them that she had decided that there were clear and compelling reasons why the Government felt unable to implement these recommendations in full. She explained that the full award could be "accommodated within cash limits only at the cost of significant compensating reductions in the expenditure on the health service which would entail an unacceptable reduction in the standards of health care." The Government decided, therefore, to implement increases as would constrain the award within an average of $6 \%$, the individual recommendations being so set as to reflect the pay relativities within the profession established by the Review Body's report.

(9.2) On 2 June 1981 representatives of the Association, together with representatives of the British Dental Association, met the Secretary of State to discuss the Prime Minister's decision. Among the points made to the Secretary of State was the feeling that on this occasion doctors and dentists were being used as a regulator of the economy. The DDRB had been told by the Health Departments that "a relatively high pay increase for doctors and dentists might stimulate similar demands from the representatives of other NHS groups." The Secretary of State told representatives of the two professions that it was most certainly not the Government's policy that doctors and dentists should be used as an example to others. He confirmed that he attached enormous importance to the Review Body system as the best method of settling the professions' remuneration and indicated that the Government's decision was an exceptional one, taken in exceptional circumstances. The Secretary of State added that he shared the concern of the professions about the situation which could arise over the next Review Body report. However, the Government recognised that a fixed cash limit was not a satisfactory way of settling pay in the public sector in perpetuity and that a greater degree of flexibility would be needed during the next year. He fully acknowledged that an arrangement would have to be found to ensure the independence of the Review Body and the professions' confidence in the Review Body system.

(9.3) Independence of the DDRB. In the autumn of 1981

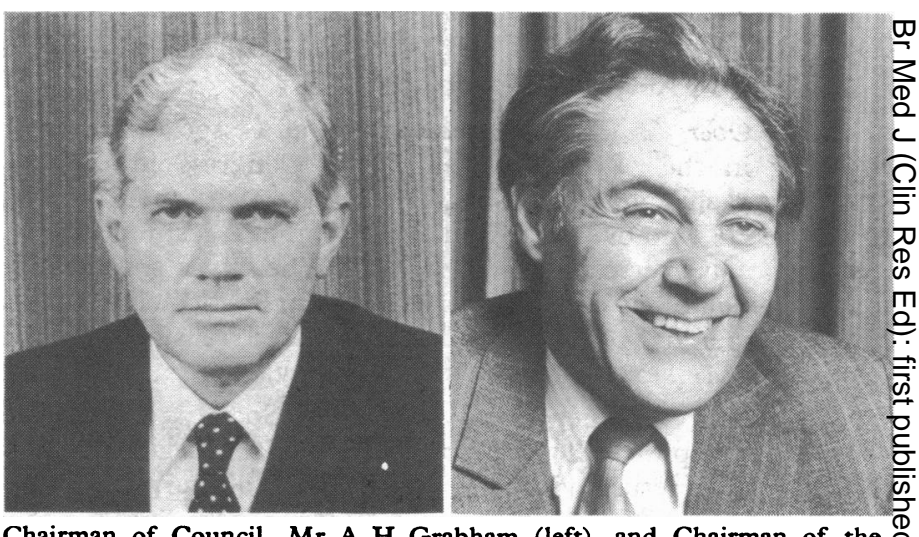

Chairman of Council, Mr A H Grabham (left), and Chairman of the $\stackrel{\varnothing}{\varrho}$ Representative Body, Dr J H Marks.

the Association's representatives met the Review Body and $\vec{\rightarrow}$ discussed matters arising from the Eleventh Report. The $\vec{\omega}$ DDRB was told that the Annual Representative Meeting in $\Omega$ 1981 had reaffirmed its strong confidence in the DDRB and $\frac{5}{3}$ that it regarded the continuance of an unfettered Review Body i

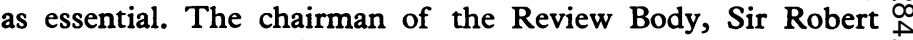
Clark, replied that it was the Review Body's intention to "continue their work in accordance with their terms of reference as long as they were able to do so on a truly independent basis.',

(9.4) The 1982 review. The Review Body Evidence Com- 을 mittee met twice towards the end of 1981 to prepare written $\omega$ evidence in support of the 1982 review. A full written $\frac{D}{O}$ memorandum was submitted to the Review Body on 4 December 1981 and was followed up by two sessions of oral evidence in $\vec{\varphi}$ January. Further written evidence is, at the time of writing, being prepared covering the hours of work of hospital junior staff and the practice expenses of general medical practitioners. Evidence on the hours of work of hospital junior staff had been sought by the Review Body from the professions following the completion of a survey into the work load and responsibility $\frac{\mathscr{Q}}{\varnothing}$ of these grades, conducted on the DDRB's behalf by the $\varrho$ Office of Manpower Economics. A further session of oral $\overrightarrow{\vec{O}}$ evidence is expected with the Review Body on this topic.

(9.5) Payments to clinical members of district management teams. Discussions have been held with the Health Departments and the Office of Manpower Economics (the body which acts as secretariat for the Review Body) on means of evaluating the work and responsibility of clinical members of district management teams (DMTs). The profession believes that the commitment of the DMT member is under-rated and that the time involved is the only practical measure of this commitment. Neverthelesss, the profession has agreed to co-operate with the $\frac{\text { ? }}{2}$ Health Departments in trying to make a critical assessment of $N$ other possible measures of the work load and responsibility of the clinical member and evidence has been submitted on this matter to the DDRB.

\section{Scientific activities}

\section{BMA prizes, research awards, and} fellowship 1981

(10.1) The Stewart Prize $(£ 75)$ was awarded to Professor A J Zuckerman, London School of Hygiene and Tropical Medicine, for distinguished research on viral hepatitis and for devising a novel and important vaccine against hepatitis $\mathrm{B}$. The Walter Jobson Horne Prize ( $£ 200)$ was awarded to Mr A G Gibb University of Dundee, for his national and international contribution to otology and the problems of deafness in both young and old.

(10.2) In 1981 the following awards were made :

Helen Tomkinson Award ( $£ 2200)$ to $\mathrm{Mr} \mathrm{T}$ Cooke, Southampton General Hospital, for research into the kinetics and functional changes in preneoplastic colonic epithelium.

Brackenbury Award $(£ 500)$ to Dr I G Barrison, Charing Cross Hospital, for research into the hazards of moderate drinking in pregnancy and the effects of educational intervention on alcohol abuse in pregnancy.

Insole Award ( $£ 250)$ to Professor D Heath, Royal Liverpool Hospital, for the preparation of a film "Astronomers above the clouds" dealing with aspects of acclimatisation to high altitude by astronomers.

Middlemore Award ( $£ 500)$ to Dr P P Ray $\stackrel{\mathscr{\complement}}{\rightarrow}$ Chaudhuri, Leicester Royal Infirmary, for research into the dominant macular dystrophy $\overline{0}$ with neovascular membrane.

Nathaniel Bishop Harman Award $(£ 500)$ to $\stackrel{\odot}{\stackrel{Q}{Q}}$ Dr R C Spiller, Central Middlesex Hospital, $\varrho$ for research into the mechanisms of diarrhoea associated with enteric feeding.

Edith Walsh and Geoffrey Holt Awards ( $£ 1000$ each) to Mr C A C Clyne, Southampton General Hospital, for research into the histochemical and capillary changes in gastrocnemius muscle in patients with peripheral vascular disease; and to Mr J S S Stewart, 
Royal Albert Edward Infirmary, Wigan, for the application of microcomputers to patient monitoring, using signal analysis of blood pressure and respiration wave forms to derive $\mathrm{HR}, \mathrm{BP}, \mathrm{RR}$, and other parameters, and to predict sudden deterioration by trend detection and other methods.

(10.3) The T V James Fellowship ( $£ 7200$ ) was awarded to Dr D J R Morgan, North Middlesex Hospital, for research into the role of type I allergic reactions in exacerbations of asthma and chronic bronchitis assessed by measurement of mediators and immunoglobulin $\mathrm{E}$ in sputum.

\section{Medical effects of nuclear war}

(10.4) In 1981 the ARM asked the Board of Science and Education to review the medical effects of nuclear war and the value of civil defence. The board appointed a small working party which is studying the blast, thermal, and immediate ionising radiation effects of nuclear weapons; the nature of clinical problems, both immediate and delayed, likely to be caused by the detonation of nuclear weapons over the UK; the mortality and morbidity consequent upon nuclear attack patterns in the UK; the immediate and longterm psychiatric effects on survivors of the nuclear attack; the probable effects of the nuclear attack on the organisation, structure, and management of the Health Service; and relations between the National Health Service and organisations involved in civil defence.

(10.5) The working party invited the submission of evidence, and written evidence was submitted by 60 organisations, including the Home Office, Ministry of Defence, and DHSS. Oral evidence is also being heard. The working party estimates that its study will be completed in 1983.

\section{Use of computers in the medical profession}

(10.6) The requirements for the transmission of data held in computers between NHS users have been considered. The Council believes that there must be common pathways for collecting and disseminating information electronically. A major firm of computer consultants will act as technical advisers in formulating a recommended standard protocol for data transmission. The protocol will be concerned primarily with transmission between small computers of the kind likely to be in use in general practice, but it will also take account of the large volume of data transmission requirements of hospital and other institutions in the NHS The DHSS, the Steering Group on Health Services Information (Korner Committee), and the Department of Industry have given their support and there will be no cost to the Association in the development of the protocol

\section{Medical audit}

(10.7) The concept of medical audit is widely accepted in the profession and many crafts are already introducing audit in their own practices, departments, and districts. A favourable response was received to the letter the Association sent to deans of medical schools and regional postgraduate deans in May 1981 asking them to provide more

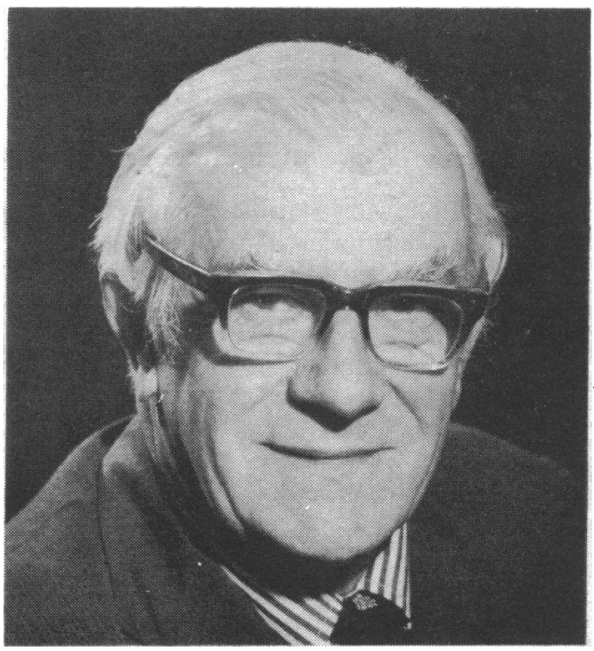

Sir John Stallworthy, chairman of the Board of Science and Education.

teaching and educational programmes relevant to professional self-assessment. Many royal colleges are holding conferences and seminars on continuing education and assessment of standards of practice and it is hoped that they will give still more encouragement to the concept of medical audit-for example, by granting training recognition only to those hospitals which provide facilities for medical audit.

\section{Seat belts; alcohol and drug abuse;} smoking

(10.8) The Government has at last accepted the need to make the wearing of seat belts compulsory for drivers and front-seat passengers in motor vehicles. This is something which the Association has been urging successive governments to introduce fo nearly a decade. The implementation date wil probably be in the summer of this year. The Medical Commission on Accident Prevention is preparing guidelines on medical exemption, the need for which is likely to be rare and of a temporary nature. (See also paragraph 20.12 under private practice.)

(10.9) The Council welcomed the booklet The Problem Drinker at Work prepared by the Health and Safety Executive, the Health Departments, and the Department of Employment. Discussions are continuing with representatives of the Trades Union Congress and the Medical Council on Alcoholism to identify areas of common interest in dealing with the problems of alcoholism.

(10.10) The British Multiple Retailers' Association and the Advertising Association have been invited to comment on the effects of advertising alcohol in supermarkets.

(10.11) The Council is maintaining its pressure on the Government to revise its policy on smoking, in relation to taxation, advertising, and sponsorship. Antismoking campaigns have previously relied on the presentation of purely scientific evidence but these need to be reinforced by encouraging smokers to alter their attitudes to the habit. A leaflet has been sent to many organisations to encourage the development of stop-smoking groups which could be organised by personnel managers, company doctors and nurses, trade union representatives, and other members of staff.

\section{International Year of Disabled People} (1981)

(10.12) The International Year of Disabled People stimulated enormous interest in the ways by which the lives of disabled people could be improved and the Council is concerned that the end of this special year should not see the end of commitment by organisations and groups working for the improved services for the disabled. Particular problems can arise from the division of responsibility between health departments and local authorities in providing facilities for the disabled and a briefing paper has been circulated widely to members of Parliament who have a special interest in this subject.

\section{British Life Assurance Trust (BLAT)}

(10.13) BLAT has had a busy session. It has contributed a weekly health cartoon strip to Woman's Realm (readership of two million); the first units of a correspondence course for GPs working part time as occupational physicians were produced in collaboration with the University of Manchester; and the trial began in 20 nursing training institutions of a BLAT-produced teaching pack aimed at affecting attitudes towards cancer.

(10.14) The World Health Organisation requested BLAT's help in the training of traditional midwives, the teaching of natural family planning, and the production of a guide to management improvement techniques in the health services. Requests for lectures to be given or for papers to be presented were received from all over the world. The more routine activities of BLAT continued unabated. Over 3000 film loans were made, and more than 10000 publications were sold. The financial turnover exceeded $£ 300000$, representing a four-fold increase in the last five years, therefore demonstrating the value placed upon BLAT's activities in health and medical education.

\section{Nuffield Library}

(10.15) Librarian. Mr F M Sutherland retired as librarian at the end of June, having been librarian since 1960 . He was succeeded by his deputy, Mr D J Wright.

(10.16) Computer-based information retrieval service. The most important development in the Nuffield Library in 1981 was the introduction of a computer-based information retrieval service. This enables the library to process literature searches faster and more thoroughly, and 47 computer searches have been completed since the computer terminal was acquired at the end of September: 331 manual searches have also been processed. The computer searches partly account for the increase in photocopies made during the year, 57000 sheets - an increase of more than 3000 over 1980. Users are charged a fee for the photocopying service.

(10.17) Classification. A start has been made on changing the classification scheme for books in the reading room from the Barnard scheme to the National Library of Medicine scheme. At the same time the long overdue weeding of the shelves is being 
carried out. This has so far resulted in over 5400 books being recatalogued and relocated in a storeroom. But it has delayed the cataloguing of new books, and only 525 have been processed this year. The essential revision of the bookstock has not interfered with services to readers, and the library's staff has continued to issue books and attend to readers at roughly the same rate as the previous year.

(10.18) Winthrop Laboratories. Through the generosity of Winthrop Laboratories a new top-security showcase has been acquired for the library, with a view to displaying some of the library's rich collection of older material. In hand at the moment is a project to microfilm some of the scarce material held by the library and other departments of the BMA.

\section{Joint Formulary Committee}

(10.19) The third edition of the new British National Formulary was published in March and will continue to be revised at approximately six-monthly intervals. The $B N F$ is sent free of charge to all clinical doctors working full time in the National Health Service, and can be bought from the Association by others. A new version of the Dental Practitioners' Formulary, for which the Joint Formulary Committee is responsible, is being produced in similar format to the $B N F$.

\section{Senior hospital staff}

\section{Siting of contracts}

(11.1) The CCHMS has strongly opposed the Secretary of State's attempt to move consultant contracts away from region under the reorganised NHS and has welcomed the Secretary of State's decision announced in October 1981 that consultant contracts should continue to be held at region. The contracts of consultants in teaching hospitals will be held by the teaching districts, and those of consultants presently working in teaching areas but who, after restructuring, will be working in non-teaching districts will pass to region.

\section{Terms and Conditions of Service Handbook}

(11.2) A revised Terms and Conditions of Service Handbook was published by the DHSS in April 1981 as the culmination of more than two years of negotiations. It was issued free of charge by each health authority to those hospital doctors in its employ. Hospital practitioners and clinical assistants received the relevant paragraphs only on request. The handbook clarifies those passages of hospital terms and conditions of service which had proved to be unclear and it contains some new agreements. The most significant new agreements are concerned with categories I and II, the assessment of duties for maximum part-time and part-time practitioners, application of the agreement to locums, and incremental credit. The CCHMS is aware that any attempts at clarification of existing terms and conditions of service might inadvertently place practitioners at a disadvantage and a "no detriment" clause was therefore incorporated.

\section{Health Service complaints procedure}

(11.3) Following Parliamentary pressure the Joint Consultants Committee and the DHSS reached agreement on a new Health Service complaints procedure. The appropriate circular, $\mathrm{HC}(81) 5$, was issued in April 198 and became operative in September 1981 There are three parts of the procedure, the third part of which deals with complaint about the way in which hospital medical and dental staff have exercised their clinica judgment. It allows for an independent professional review of the case by two "second opinions" appointed by the Joint Consultants Committee, one of whom would be nominated by the CCHMS. Those giving the "second opinions" should be consultants in active practice in the specialty or specialties appropriate to the case and at least one should be a doctor working in a comparable hospital in another region. "Second opinions" are not published but are reported confidentially to the regional medical officer, who is responsible for taking appropriate action.

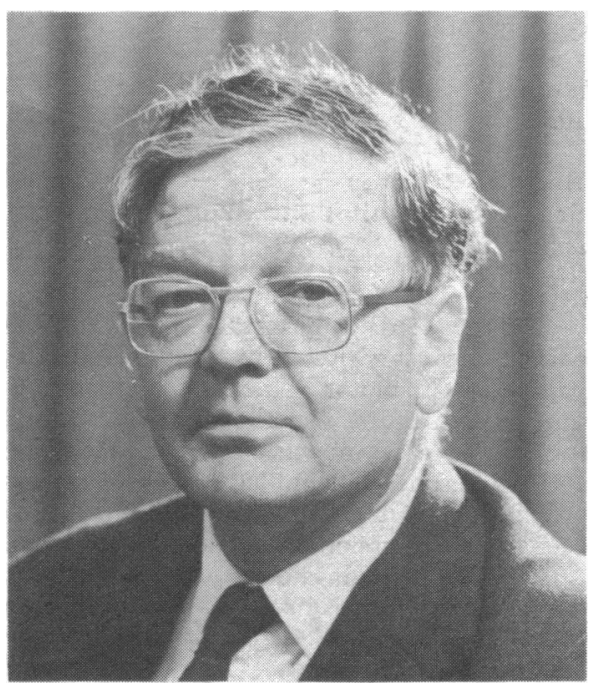

Mr David Bolt, chairman of the CCHMS.

\section{Motor car allowance}

(11.4) Last year a revised milage allowance system for hospital doctors was introduced. The system is based on the AA schedule of motoring costs and is designed to reimburse a maximum of $75 \%$ of standing charges for the regular user; most consultants are now eligible for regular-user status. There has been considerable discussion of the merits of the system and particularly its effects on the consultant who does a high milage. The CCHMS is therefore continuing discussions with the DHSS.

\section{Hospital Consultants and Specialists Association (HCSA)}

(11.5) Last session the CCHMS agreed, in principle, to proposals enabling the HCSA to participate in its work, which would have given the HCSA voting rights and two years of guaranteed membership of the major subcommittees. It asked the HCSA to clarify its attitude towards General Whitley Council recognition, which the $\mathrm{HCSA}$ regarded as a condition precedent to participation in the CCHMS. During the discussions it became apparent that the HCSA had received a letter from the Secretary of State for Social Services which appeared to suggest that inclusion of the HCSA in the CCHMS structure could result in its being recognised as a "Whitley" organisation. The CCHMS has always held that the introduction of a second organisation into the negotiating structure would weaken the negotiations. It welcomed the support of the Council in October 1981 for its view that the participation of any organisation in its work should not result in that organisation being formally recognised as representing senior hospital staff. Upon being informed of this the HCSA indicated that it did not wish to continue the discussions and the Council subsequently endorsed the action taken by the CCHMS.

\section{Model contracts}

(11.6) The model contract for consultants was published in November 1979 and appeared as appendix D to DHSS circular PM(79)11. It was understood that the model contract would be used by health authorities for every consultant subject to minor amendment as warranted by exceptional local circumstances. The CCHMS was therefore surprised to learn that some health authorities were refusing to conform to the model form of contract and that in some cases seriously detrimental changes had been introduced. In one case negotiation with the DHSS failed to resolve the problem and the matter was brought to the attention of the Council. It has since been resolved but the CCHMS is continuing to monitor the use of the contract in all regions.

\section{Staffing structure}

(11.7) The report of the Parliamentary Select Committee on medical education, chaired by Mrs Renée Short, was published in October 1981 and has been regarded as an important contribution to the manpower problems of the profession. The CCHMS produced a detailed commentary on the report in January 1982. The Government's own response was published in February 1982 and endorsed most of the select committee's recommendations. However, the CCHMS is gravely concerned over several aspects of the select committee's report, most importantly the recommendations on the expansion of the consultant grade and the Chief Medical Officer's initiative on manpower arising from the report. The CCHMS is committed to a resolution of the manpower problem and a controlled expansion of the consultant grade but is unhappy over the lack of clarity in the select committee's report on how the doubling of the consultant establishment will be implemented or distributed between specialties. It is because of these fears that the CCHMS is concerned by the Chief Medical Officer's initiative on manpower, which it believes could have an adverse effect on the standards of patient care. The CCHMS has therefore written to chairmen of regional health authorities challenging the assumptions-particularly those relating to finance-contained in the letter sent to chairmen by the CMO. 


\section{Junior hospital staff}

Fourth Report of the House of Commons Social Services Committee (Short Report) on Medical Education

(12.1) The Hospital Junior Staff Committee (HJSC) has warmly welcomed the recommendations in the Short Report, with the exception of recommendation 9 on medical school intake. It believes that the current and projected UK medical school output will bring an increase in medical unemployment.

(12.2) The HJSC supported the recommendation that a much higher proportion of patient care should be provided by fully trained medical staff by increasing the number of consultants and decreasing the number of junior doctors. However, it was concerned that arrangements for restructuring must be such as to avoid further unemployment. The committee wishes to see no further increase in the number of SHO posts, and it believes that it is essential for NHS honorary contract holders in academic posts to be controlled through the central and regional manpower committees.

(12.3) The committee is gratified that the majority of the recommendations in the report support the evidence which the HJSC submitted to the Social Services Committee. There are a few items on which opinions differ but the HJSC believes that taken as a whole the report's recommendations offer a wellbalanced solution to hospital career structure problems.

\section{Medical unemployment}

(12.4) As part of a joint exercise with the favour legislation a week. The HJSC does not Permanent Committee on Manpower the support the Junior Hospital Doctors (RestricHJSC is trying to obtain reliable information tion of Hours) Bill. This Bill sought to enforce on the extent of medical unemployment. A a phased reduction to 35 hours a week but was questionnaire has been prepared which is withdrawn. The Chief Medical Officer of the being sent to a sample of doctors to try to find DHSS held a conference on 12 February to out how extensive this problem has become. discuss the hours of work of junior hospital Recent Government figures suggest that un- doctors at which members of the HJSC employment is rising and there are now more attended and participated.

than 1000 persons registered with the Department of Employment seeking work as medical practitioners. This serious problem will be exacerbated by the Government's intention to continue to expand medical school intake to 4080 a year (see also para 22.2).

\section{Remuneration}

(12.6) The evidence to the DDRB for the 1981 review included a strong case for a

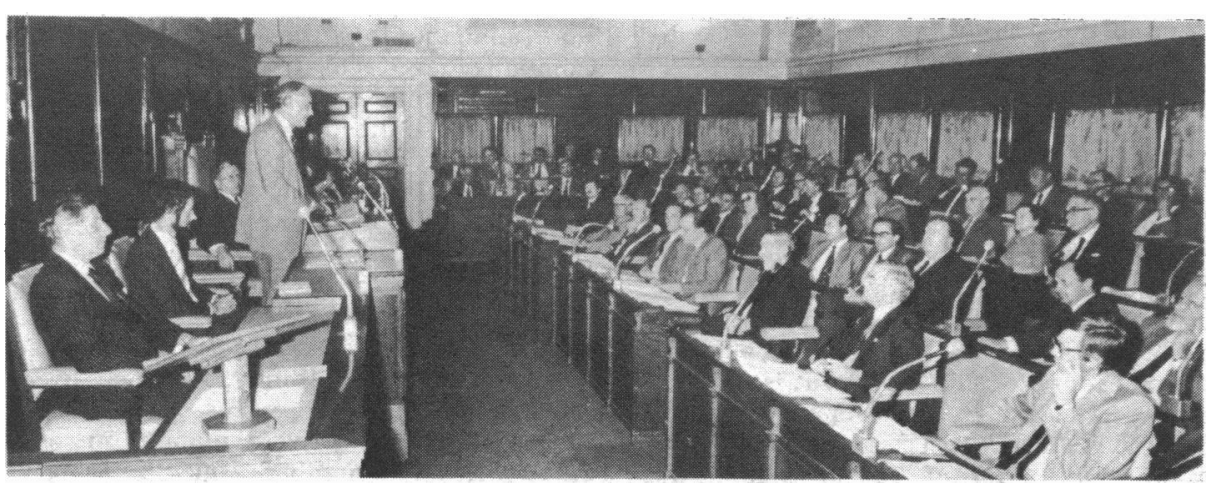

Dr Gerard Vaughan, former Minister of State for Health, addressing the CCHMS in October 1981. substantial increase in remuneration for duties in excess of 40 hours a week. The DDRB was unable to reach any conclusions on that occasion as it lacked up-to-date information on work patterns in the training grades. A survey of the actual work and responsibilities of the grades concerned has been carried out by the Office of Manpower Economics by sampling junior hospital doctors in 16 health districts. Each doctor was asked to complete a questionnaire form so as to provide a simple record of hours worked and the type of work carried out over a seven-day period.

\section{District hospital junior staff committees}

(12.7) Under the reorganised NHS more power is invested in DHAs. The HJSC believes it is essential for junior hospital doctors to be represented effectively at district level. The HJSC is strongly in favour of district HJSCs being set up under the aegis of the Association to safeguard the interest of hospital junior staff which may be adversely affected by the local decisions.

\section{Women in medicine}

(12.8) Concern at the need to provide adequate facilities for part-time training and career opportunities for doctors with domestic commitments prompted the HJSC to appoint a working party, chaired by Dr Anne Blyth, to consider the problems. The working party will hold a special conference on the issues in May and will conduct a survey of doctors in the light of the views expressed at the conference.

\section{General practice}

\section{National Insurance certification}

(13.1) The General Medical Services Committee has successfully concluded its negotiations with the Department of Health for an end to short-term certification. The Government has agreed that, with effect from 14 June 1982, GPs will no longer be required under their NHS terms of service to issue certificates in support of claims for social security benefit for illnesses lasting less than seven days. A system of self-certification for short periods of incapacity, with checks on those making frequent claims for benefit, is to be introduced. The GMSC believes that such arrangements will exercise greater control over absenteeism and will benefit patients with real medical problems. It is intended that the arrangements will continue to operate under the Employers' Statutory Sick Pay Scheme (ESSP), which the Government plans to bring into effect in April 1983.

\section{Family practitioner committees}

(13.2) Despite widespread opposition, the Government decided to grant family practitioner committees independent health authority status after reorganisation of the 
administration of the NHS in April 1982. Although the decision may not be implemented before the spring of 1984 , because of pressure on the Parliamentary timetable, it is hoped that full co-operation will be given to any interim arrangements which are made. The profession welcomes the Government's commitment to the primary care sector which is illustrated by this decision.

\section{Primary health care}

(13.3) The GMSC will soon begin discussions with the Department to identify those recommendations in the Acheson Report on Primary Health Care in London, and in similar recent reports, on which action can be

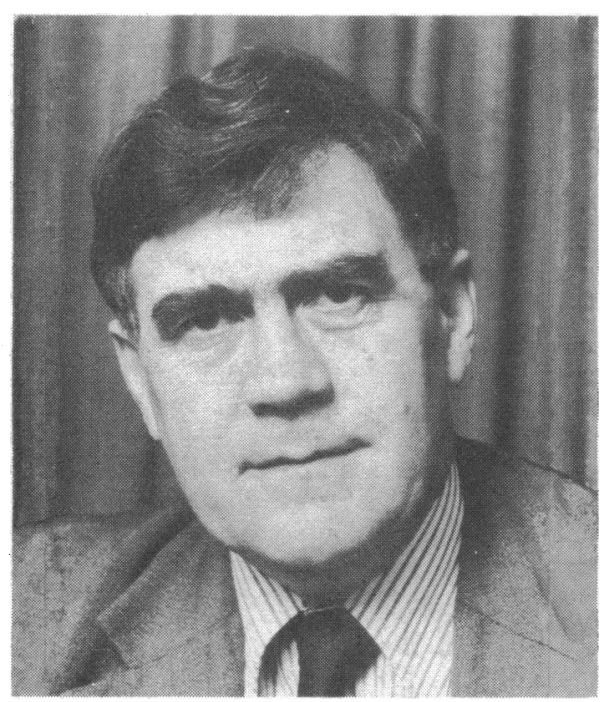

GMSC chairman, Dr John Ball.

taken in anticipation of the longer-term aspects of these studies. The GMSC believes that, in general, solutions should be sought which can be applied to other parts of the country with similar problems and that the impetus given by publication of the reports must not be lost.

\section{Hospital practitioner grade}

(13.4) The report of the Select Committee on Medical Education (Short Report) supported the hospital practitioner grade and this was welcomed by the GMSC. This is an important factor in hospital staff restructuring and should result in a marked expansion of the grade.

\section{Treatment of overseas visitors}

(13.5) The GMSC has discussed in detail with the Department of Health the imposition of charges for general medical services on bverseas visitors. However, it was not possible to establish arrangements for the collection of such charges which were satisfactory to both the GMSC and the Department and it has been decided that no change in the present "good Samaritan" policy should be made. This enables GPs to provide immediately necessary treatment under the NHS or to offer private care.

\section{Community medicine}

\section{Career structure and training of} community health doctors

(14.1) The ARM 1981 asked the Central Committee for Community Medicine (CCCM) to continue to negotiate a career structure for community health doctors as a matter of urgency and to report back not later than the ARM 1982. The CCCM has approved, in principle, a report prepared by its Community Health Doctors Subcommittee and has agreed that discussion should be reopened with the Department of Health on the formation and funding of a joint training programme in community health. The report recommends the maintenance and development of community health services to meet present and future needs and the establishment of a career structure and training programme for these doctors. A summary of the report was published in the $B M \mathcal{F}$ of 30 January (p 360). The other craft committees are being consulted and it is hoped that rapid progress will be made towards the implementation of the recommendations contained in the report.

\section{Contracts of community physicians}

(14.2) It is the policy of the Representative Body that the contracts of community physicians and clinical consultants should be held by the same authority. Before the Secretary of State had announced that the majority of consultant contracts would be held at regional level, the CCCM had agreed with considerable reluctance that district medical officers' contracts would provisionally be held at district level in order to enable district medical officers to be appointed as soon as possible and take an active part in establishing the new service at district. It is proposed to ask the 1982 Conference of Community Medicine for its views on this action and a further report will be made to the Representative Body.

\section{Community physicians and NHS reorganisation}

(14.3) The CCCM has published a paper on the function of the community physician in the new district. It was circulated to the chairmen of the new DHAs in the summer of 1981 , many of whom wrote in appreciation of it. In producing the document the CCCM bore in mind the decision of the ARM 1981 that the number of established posts for community physicians should be sufficient to provide the range of expertise required to fulfil the essential functions of community medicine.

(14.4) Protection arrangements for staff who may have been affected by the restructuring were negotiated in the Reorganisation Committee of the General Whitley Council, on which the profession was represented. It was agreed that each region should determine the procedure for filling posts. It is the policy of the CCCM that wherever possible community medicine posts should be filled by "slotting-in." Out of 194 district medical officer posts in England, 144 were filled at the first round. It was subsequently agreed that unfilled DMO posts could be advertised nationally with effect from 22 January 1982, with a closing date for application not earlier $?$ than 8 February 1982. Competition for these $\mathbb{D}$ posts was open to any suitably qualified and

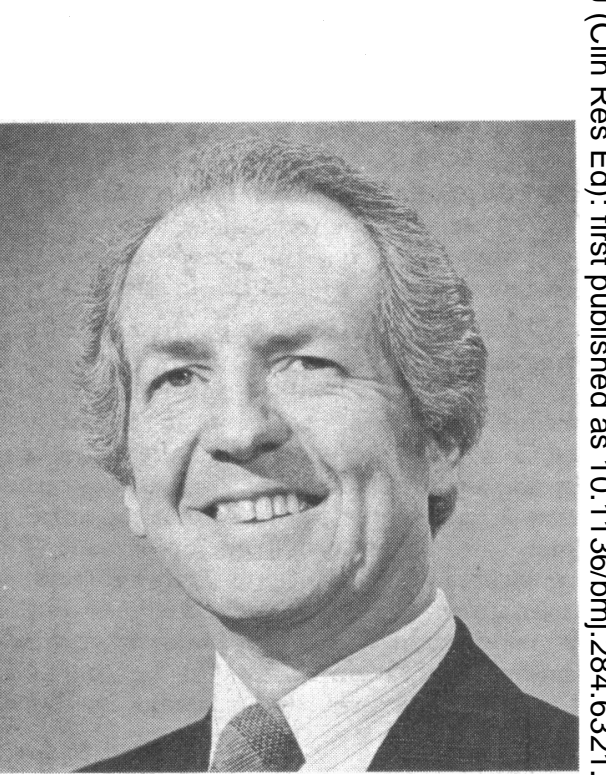

Chairman of the CCCM, Dr Stuart Horner.

experienced doctor currently employed by the NHS in England and Wales, including $\vec{\bullet}$ those who had already obtained DMO posts. In addition, it was agreed that existing area medical officers who had not yet obtained posts should have the right to be shortlisted for any vacancy for which they might apply under those arrangements. The number of early retirements arising from restructuring is likely to have a serious effect on manpower in what is already a shortage specialty and the Community Medicine Consultative Committee has been asked to give urgent consideration to long-term planning in the specialty.

\section{Medical academic staff}

\section{University finance}

(15.1) The Council is extremely concerned about the effect on medical education of the severe cuts in grants to universities which were announced by the University Grants $O$ Committee (UGC) on 1 July 1981. The UGC said that it could no longer "offer to clinical medicine the protection which it has hitherto enjoyed in relation to the general decline in resources." The Council, through its Medical Academic Staff Committee (MASC), has gathered information on the effect of the cuts in different medical schools. At the beginning of the academic year, when decisions were being made on savings, most universities had started to freeze vacant posts and were encouraging early retirement. Cuts of the order of $10 \%$ to $15 \%$ were required in some universities and a number of medical schools, for example, Aberdeen, found that they would 
need to lose up to 20 academic posts. It soon became clear that some redundancies would be inevitable. The effects of the cuts in the London medical schools have been compounded by the current reorganisation of the Health Service, which affects postgraduate hospitals and which will also lead to job losses.

The chairman of MASC has met the vicechancellor of London twice to seek assurances on the redeployment of medical academic staff in London.

(15.2) The possible reduction in the numbers of medical academic staff will seriously affect the quality of medical education in this country and will reduce staff/ student ratios, since medical schools, unlike other faculties, cannot opt to reduce student numbers. When clinical academic posts are reduced, NHS patients cared for by medical academic staff in teaching hospitals are likely to suffer and NHS colleagues will be expected to take on extra work. It was not until the end of January 1982 that the Government approved a redundancy compensation scheme for academic staff, for whom there had previously been no provision beyond the minimal amounts available under the Employment Protection (Consolidation) Act 1980. The status of academic contracts which confer tenure "for life" has never been tested in the courts. The Council sought a legal opinion, which indicated that there was no certainty of additional compensation for prematurely and unilaterally ending such contracts.

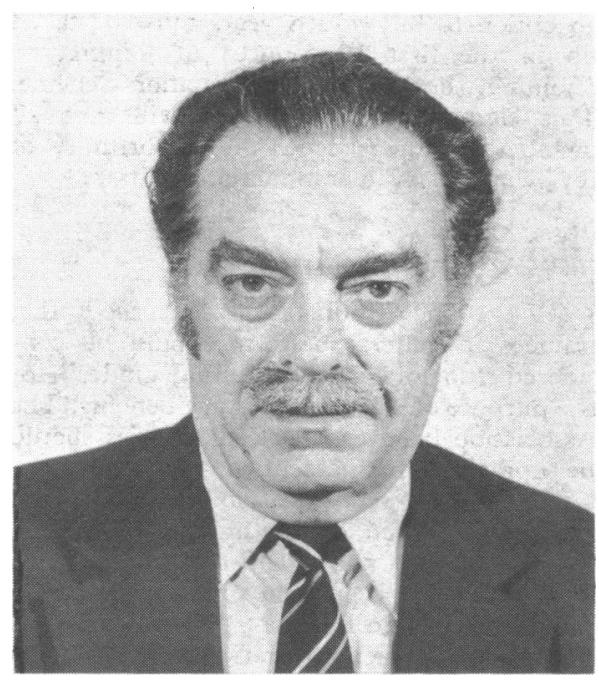

Professor J P Payne, chairman of MASC.

(15.3) The Council expressed its concern to the chairman of the Medical Subcommittee of the Committee of Vice-chancellors and Principals (CVCP) and representatives of MASC met the Parliamentary Under Secretary of State at the Department of Education and Science as well. It is becoming clear that medical faculties of universities are suffering most because they have a high staff turnover and a higher proportion of vacant posts can be allowed to remain unfilled in order to save money. Although the Parliamentary Under Secretary of State listened sympathetically he did not promise action to alleviate the consequences to the medical faculties. The Council wrote to the UGC in january deploring the implementation of the university cuts, which were effectively discriminating against faculties of medicine and which would have an adverse affect on the clinical care of NHS patients provided by clinical academic staff. The Council has urged the UGC to ensure that the discrimination ceases.

\section{Extra payments scheme for medically qualified preclinical teachers}

(15.4) There has been a poor response to the scheme proposed by the CVCP in 1980 for extra payments to be made to medically qualified preclinical teachers undertaking clinical teaching sessions. The scheme had been seen as a small step forward in a long campaign to improve recruitment and retention of medically qualified staff in preclinical departments. In only four schools are payments being made. The Council has collected information as to why the scheme has not been implemented. The reasons given include lack of cash, opposition from non-medically qualified colleagues, rejection by university authorities, and limited eligibility under the strict guidelines laid down by the CVCP.

(15.5) The difficulty of recruiting and retaining medically qualified staff in university preclinical departments continues to concern the Council. It has written to medical deans emphasising that short-term demonstrato posts, which sometimes provide the undergraduate's only encounter with medically qualified staff in preclinical departments, are particularly at risk when a policy of freezing vacant posts is adopted. A possible solution to the long-term problem would be to assimilate medically qualified preclinical staff to the UGC salary scale for clinical academic staf with honorary NHS contracts below consultan level. Ways of achieving this are being investigated.

\section{Clinical academic salaries}

(15.6) The 1981 DDRB award was quickly implemented for clinical academic staff through the Clinical Academic Staff Salaries Com mittee (CASSC), on which MASC's negotiators have been particularly active this session.

(15.7) The negotiators continued their efforts through CASSC to achieve broad comparability of remuneration between clinical academic staff and NHS consultants. The discrepancy has widened in recent years with the introduction of the right for whole-time NHS consultants to undertake private practice. The DDRB in its Eleventh Report stated that its recommendations took account not only of basic salary, but of the total remuneration of NHS consultants, that is, including such items as domiciliary visits and family planning. The fact that these fees are not available to clinical academic staff provides strong grounds for enhancing the salaries of clinical academic staff in order to restore broad comparability. However, the economic climate in the universities is now so unfavourable that the possibility of an enhancement seems remote. Indeed the principle of broad comparability may itself be under threat. MASC continues to press the CVCP on this matter and has detailed the recruitment difficulties and consequential decline in standards which will result from significant discrepancies in remuneration.
Model honorary contract for junior clinical academic staff

(15.8) After concern had been expressed by junior academic staff about the varying forms of honorary contract or "letter of authority" with which they were being issued, MASC has produced a draft model contract, designed to give full medicolegal cover as well as making the transfer easier between NHS and academic appointments by ensuring continuity of terms and conditions of service. This draft contract is now being discussed between representatives of MASC and the HJSC.

\section{Academic POWARs}

(15.9) In order to strengthen BMA representation in medical schools, and to increase the flow of information to medical academic staff on issues affecting their terms and conditions of service, clinical academic POWARs are being appointed in each medical school. The POWAR network will be based on the network of Conference of Medical Academic (COMAR) Representatives which already exists in the medical schools.

\section{Occupational health}

(16.1) The Association's publication The Occupational Physician is being revised and will be available later in the year in a loose-leaf edition. It will take into account changes in sickness certification procedures and will include new sections on the retention of health records, a model contract for occupational physicians, and termination of workers' contracts on grounds of ill health.

(16.2) A draft guidance circular on the provision of occupational health services for NHS staff is at present under discussion with the DHSS. Initially, the Department proposes the appointment of one consultant physician specialising in occupational health for each NHS region.

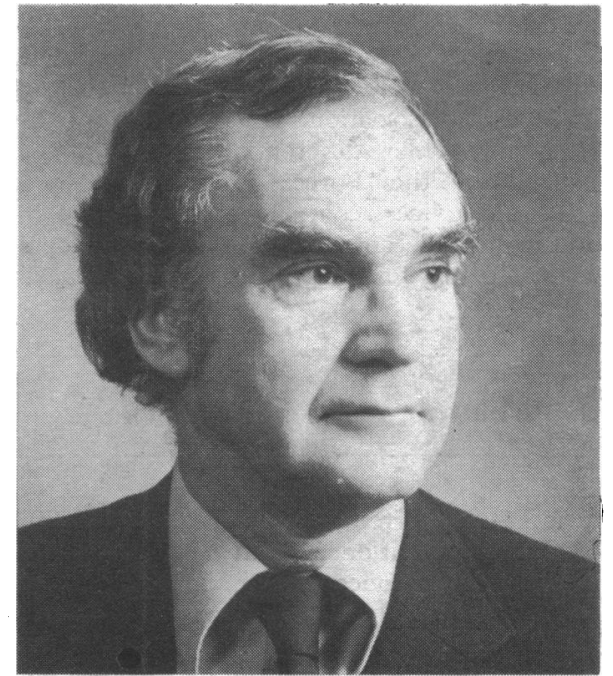

Dr J L Kearns, chairman of the Occupational Health Committee. 
(16.3) Negotiations with nationalised industries have been protracted but their outcome is satisfactory. The National Coal Board has agreed to pay its medical officers above the BMA recommended minimum rates and the British Railways Board has moved nearer to BMA recommended rates.

(16.4) A large number of negotiations have been carried out on behalf of general practitioners who are employed by small factories under the Health and Safety at Work Act 1974.

(16.5) Work has begun on compiling a comprehensive list of doctors working in occupational health.

\section{Armed Forces}

(17.1) The supplement to the Tenth Report of the Armed Forces Pay Review Body (AFPRB) was published in August 1981. It recommended an average increase of about $7 \%$ for service medical officers. The recommendations were based on the recommendations of the Doctors' and Dentists' Review Body for NHS general practitioners as modified by the Government. As a result, doctors and dentists in the armed Forces received lower increases than their fellow officers. The Association asked the Prime Minister to intervene so that serving medical and dental officers would receive the same increase as their service colleagues. The Prime Minister refused to intervene despite the fact that the Government had exempted the armed Forces from the cash limits which affected NHS doctors and dentists. The Prime Minister indicated that it was open to the Association to take up the matter again with the AFPRB in its submissions for the 1982 review.

(17.2) At present, the remuneration of the 16 most senior medical officers in the armed Forces is dealt with by the Top Salaries Review Body, while all other medical officers are covered by the AFPRB. This separation has caused serious anomalies and representations have been made to the Government for the remuneration of all serving officers to be dealt with by one review body.

(17.3) Evidence given to the AFPRB this year includes a claim for an earnings-related pension, and emphasises that doctors in the armed Forces are only able to buy added years of pensionable service at a discriminatory rate. The Association believes that only by achieving wider differentials in the higher ranks can the Forces maintain balanced medical services, covering the military commitment while ensuring the training recognition necessary for satisfactory career prospects.

\section{Ophthalmic medical services}

(18.1) The fee payable to an ophthalmic medical practitioner under the General Ophthalmic Services was increased to $£ 4.50$ from April 1981, this figure including an expenses element of 99p. An inquiry into the expenses incurred by OMPs in 1980 has now been conducted and the results forwarded to the Review Body. It is hoped that this inquiry will provide a starting point to enable the Review Body to estimate the expenses to be included in the gross fee with effect from April 1982. In the past this has been done by negotiation with the Health Departments.

(18.2) Representatives of the Ophthalmic Group Committee have met the Central Committee for Community Medicine and the Central Ethical Committee to resolve problems arising out of the inappropriate handling of the Form BD8 which has in some cases led to a potential infringement of medical confidentiality. This form is used in the registration of blind and partially sighted persons. Details of the agreement reached are being sent to district medical officers, members of the Ophthalmic Group, and to the DHSS.

(18.3) The profession is concerned at the apparent attitude of the Department of Health to the ophthalmic medical practitioner in the General Ophthalmic Service. The Ophthalmic Group Committee will remind the Department of the accepted concept that an OMP brings an overall medical expertise not possessed by ophthalmic opticians.

(18.4) The Ophthalmic Group Committee has been particularly concerned with matters of manpower. It welcomes the production of a document from the Faculty of Ophthalmologists setting out acceptable standards, and continues its efforts to foster the return of the general practitioner to active participation in primary, secondary, and intermediate ophthalmic care.

\section{Superannuation}

\section{Widowers' pensions}

(19.1) At present widowers' pensions are only paid where the husband was dependent on his wife. The Council is disappointed that the Government can offer no hope of introducing widowers' pensions as a right for women contributors to the National Health Service

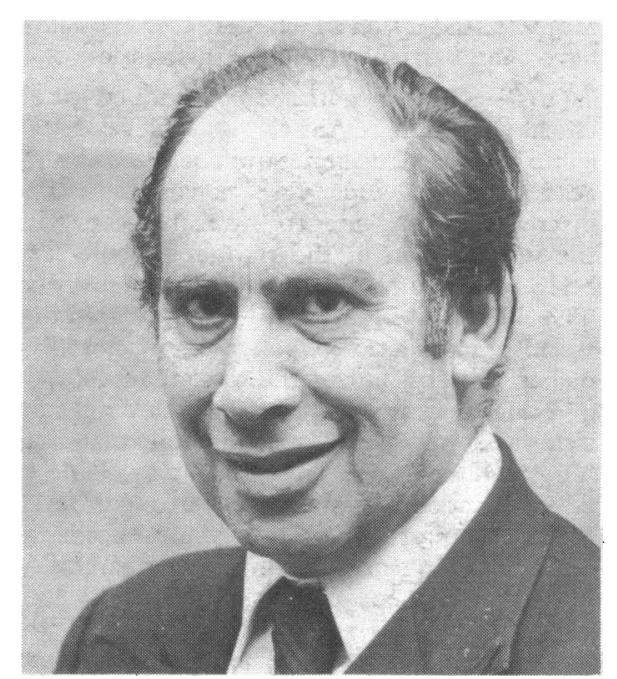

Superannuation Committee chairman, Dr B L Alexander.

Superannuation Scheme. The Government argues that this is something which can be considered only with other improvements to the scheme at some time in the future when the economy is stronger. Nevertheless, as a result of a judgment in the European Court against British Rail on a similar issue the Association will continue to exert pressure on the Government to try to secure this benefit.

\section{DMT payments}

(19.2) The Council has decided not to accept the Department of Health's offer to make payments to those serving on district management teams superannuable until an agreement can be reached with the DHSS on the introduction of a calculation method which would allow consultants to take full account of all fluctuating NHS payments earned throughout their careers. The DHSS insists that the method used to calculate the benefit should be based only on those earnings in the year before the consultant retires. The Association has proposed a method similar to the one used to calculate a general practitioner's pension so that earnings in early years are uprated and do not lose their value in real terms

\section{Buying added years}

(19.3) A more flexible scheme to enable doctors to buy added years of pensionable service is likely to be approved soon by the DHSS. When the scheme comes into operation it will allow doctors to purchase added years at almost any time during their careers in contrast to the present system, under which an option to buy added years must be taken up in the first 12 months of joining, or rejoining, the NHS Superannuation Scheme. This significant improvement will give all members of the scheme the opportunity of reviewing their superannuation position.

\section{Injury benefit}

(19.4) The Council is concerned that trainees in general practice should be considered "doctors in the training grades" for the purpose of calculating injury benefits. The Association believes that their salaries should be uprated to a percentage of the average intended net remuneration of a general practitioner when calculating injury benefit. The DHSS will not extend the arrangements to GP trainees because the original agreement referred specifically to "junior hospital doctors." An amendment is, therefore, being sought to the Injury Benefit Regulations so that trainees in general practice will cease to be at a disadvantage.

\section{Index linking of pensions}

(19.5) A Civil Service interdepartmental committee has been set up to consider the conclusions of the Report of the Inquiry into the Value of Pensions (the Scott Report). The Scott Report recommends the continued index linking of public sector pensions. The interdepartmental committee's proposals will go to the Chancellor of the Exchequer and it is hoped that the Government's conclusions will be published without delay.

\section{The sick doctor}

(19.6) The DHSS proposes to introduce legislation to safeguard the financial position

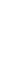

\section{.} . $\stackrel{\partial}{\partial}$ 
of those doctors suspended from the Register on medical grounds by the Health Committee of the General Medical Council. Until Parliament has approved the legislation Ministers have agreed to consider sympathetically applications from health authorities to make payments in individual cases.

\section{Redundancy payments}

(19.7) The Council was concerned to learn of women doctors over age 60 who, on being made redundant as a result of reorganisation, were not receiving redundancy payments. Their male colleagues similarly affected are entitled to redundancy payments up to age 65 . This is discriminatory as NHS terms and conditions of service are the same for men and women doctors. The Council has asked the Secretary of State for Social Services to give immediate consideration to the provision of redundancy payments on equal terms for men and women doctors who lose their employment as a result of reorganisation.

\section{Private practice}

\section{Provident associations}

(20.1) A number of meetings have been held with the representatives of the provident associations this year. They have included an expression of the Association's concern at the increasing tendency for subscribers' claim forms to be signed by the consultants who treated them instead of by their general practitioners. One of three main provident associations already conforms with the Association's policy on this issue and the other two have shown a willingness to try to conform.

(20.2) The Council has also discussed with the provident associations the responsibility for payment for the examination of prospective subscribers to health insurance schemes. On the one hand it could be argued that the position of the provident association is no different from that of the life assurance company, and that these examinations are in the interests of the association and of its subscribers. On the other hand, provident

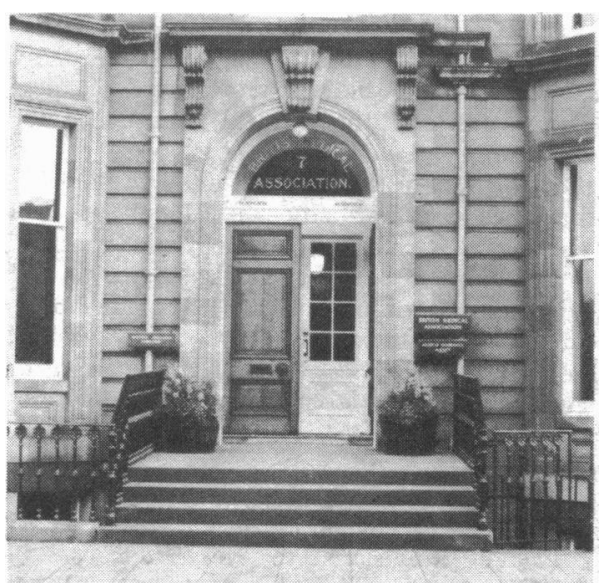

BMA Scottish House, Edinburgh. associations are non-profit-making organisations and wholly dependent for their income on existing subscribers, while charging the patient enables the doctor to vary his fee according to circumstances. It is therefore felt that this is a matter on which the Representative Body should be invited to formulate policy.

(20.3) The ARM 1981 expressed concern about differing levels of benefit offered by provident associations in different parts of the country. The Council is pleased to note that there has since been a move by the provident associations to allow equal benefits for consultant services irrespective of locality. It has been recognised that benefits offered must reflect charges levied rather than the other way about. If it is found that medical fees are higher in one part of the country than elsewhere this may be reflected in the level of benefits which the associations offer. The Council accepts that it is not reasonable to expect the provident associations to encourage individuals to oversubscribe or undersubscribe.

(20.4) Discussions have continued with the provident associations on the establishment of a primary health care insurance scheme. The success of such a scheme would be dependent upon the Government agreeing to make NHS drugs available for private patients.

\section{Choice between private and NHS care}

(20.5) One of a series of leaflets being produced by the Association explains the relationship between the NHS and the private sector. The Council has reminded the DHSS of the importance of maintaining the principle of treating private patients in NHS hospitals.

\section{Schemes for BMA members}

(20.6) The Association has again written to members commending the BUPA scheme, and discussions are continuing with Private Patients Plan to find ways by which the PPP scheme might be made more attractive to members.

\section{Increases in fees}

(20.7) The fees guide has been published in loose-leaf form as a supplement to the Members Handbook and has been well received by members. This form of publication aids rapid revision of pages of the guide when increases in fees are negotiated. A further increase has been made in recommended (category D) fees to take account of rising cost and will take effect from April 1982. During the year fees for work undertaken by doctors for central Government departments have generally been increased by $6 \%$, and one or two anomalies remaining from the restructuring exercise completed last year have been resolved. Local authority fees have been increased by a similar percentage and negotiations on the restructuring of these are continuing.

(20.8) A new agreement has been reached with the Life Offices Association for increases in fees for life assurance examinations and reports over the next three years in line with the retail price index. The increase in October
1981 was $10 \cdot 9 \%$. Fees paid by the ambulance associations were increased to take account of the full increase recommended for NHS doctors by the DDRB. The increase took effect from 1 January 1982 except for the St Andrew's Ambulance Association in Scotland, which was able to introduce the increase from September 1981. It is hoped that September can be agreed as the effective date for revision in future years.

(20.9) Discussions with the Lord Chancellor's Department on fees paid for professional witnesses have been encouraging. The maximum levels of these fees are governed by statute. Progress has been made on the introduction of a more flexible system which will, it is hoped, mean that members will no longer be out of pocket as a result of a requirement to attend court.

\section{Home Office-appointed pathologists}

(20.10) The arrangements whereby the Home Office-appointed pathologist either was paid a call-out fee by local agreement or received a retainer from the Home Office was introduced in 1932. Almost 50 years later the Home Office has agreed to the payment of an availability fee to all pathologists appointed to the list. At the same time a national agreement has been reached with the representatives of the local authorities under which call-out fees will be paid in addition for work actually performed. The Home Office has accepted that the new rate of the availability fee, $£ 1000$ a year, falls short of the true value of the work. But the Council regards it as a satisfactory first step. The agreement on call-out fees is more generous than any of those locally negotiated, which tended to vary considerably.

\section{Part-time prison medical officers}

(20.11) It has taken two years of negotiation to reach an agreement on improvements in the allowances paid to part-time prison medical officers in addition to their salary. Under the terms of the new agreement those in full medical charge of the prison-that is, where there is no full-time prison medical officer,

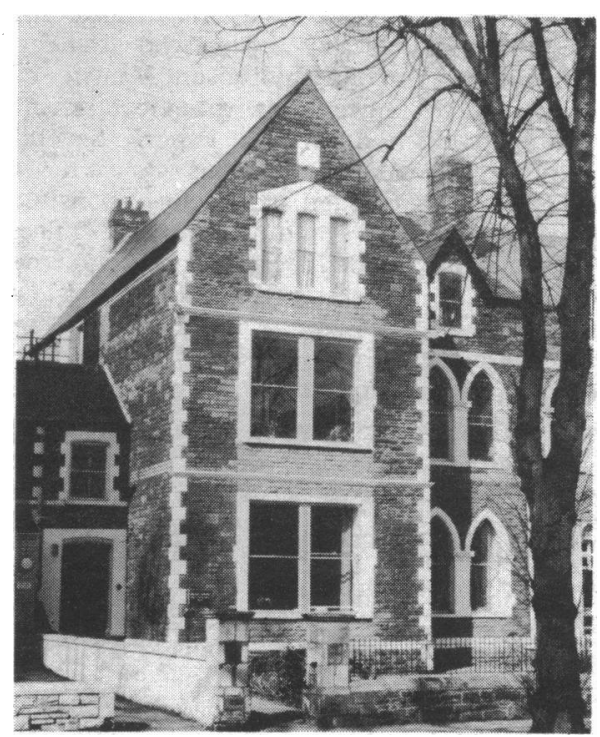


will receive an allowance of $£ 1075$ a year backdated to April 1981. Pay will be revised in accordance with the existing agreement giving a $7 \%$ increase and bringing the annual rates up to $£ 687$ for the first hour in every week and $f 458$ for each subsequent hour. Substantial increases in fees paid to doctors providing irregular services to the prison service, bringing them into line with the general schedule of fees for central Government departments, have been offered to take retrospective effect from October 1980.

\section{Medical exemptions from wearing car} seat belts

(20.12) The Council has considered the procedure by which certificates of medical exemption from the compulsory wearing of car seat belts may be issued. All that will be required, it believes, will be a certificate stating the doctor's opinion, and his estimate of the length of time for which an exemption should last. The certificate should only be given after a full medical examination and the same procedures should apply to all age groups. A suitable fee for the examination and statement is that which is recommended for a comprehensive medical examination and report in paragraph 111 of the fees guide. (See also Scientific activities, para 10.8.)

\section{Medical ethics}

\section{Confidentiality of medical records}

(21.1) The Council has welcomed the announcement that a White Paper on data protection will be published during the current Parliamentary session. The Council of Europe Convention for the Protection of Individuals with regard to automatic data processing of personal data was signed by the Government in May 1981 but it has not yet been ratified.

(21.2) A data protection conference, chaired by Sir Douglas Black, president of the Royal College of Physicians, was held at BMA House in September 1981. Representatives of the health professions, the computer industry, government departments, patients' associations, the police, and research bodies who attended were told by $\mathrm{Mr}$ Timothy Raison, Minister of State, Home Office, that the Governmen would publish a White Paper. Several participants expressed serious concern at Mr Raison's statement that the body responsible for data protection would be the Home Office. The Council made representations to the Government asking for the Minister's view to be reconsidered and urging that an independent commission be set up, responsible to and reporting to Parliament.

(21.3) The Home Office plans include a proposal for a registrar independent of the Government, who will act as an "ombudsman" where disputes arise. Although general principles of data protection will be laid down the codes of conduct to be prescribed by law as recommended by the Data Protection Committee in its 1978 report have been rejected. The Council believes that the proposed voluntary codes of practice will not prove sufficient to safeguard the confidentiality of medical information.

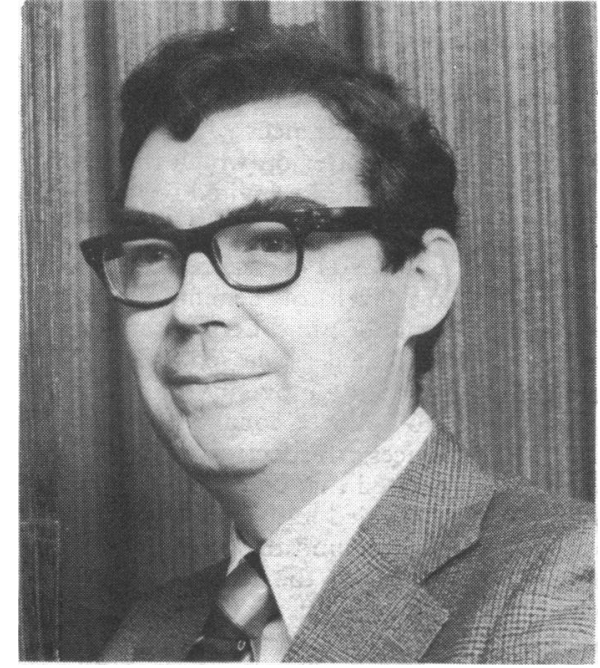

Chairman of the Central Ethical Committee, Dr M J Thomas.

\section{Child Health Computing Committee}

(21.4) Pilot trials for the child health computing scheme have been approved by the Council. Assurances have been received from the Child Health Computing Committee on aspects of the scheme which had been causing concern. Although precise locations have not yet been agreed, the trials will take place in a rural, an urban, and a mixed rural and urban area. Observers appointed by the General Medical Services Committee will have the right to stop any trial if a gross breach of confidentiality occurs.

\section{Responsibility for treatment}

(21.5) The following additional guidance on a doctor's responsibility for treatment has been approved by the Council:

(a) Where a patient chooses to consult a doctor other than his usual medical practitioner, that doctor has a duty to ensure that the patient is not already under active treatment. If the patient is under active treatment, the doctor should normally refuse to treat him unless the patient is prepared to terminate the previous clinical relationship. If the patient is not under active treatment, the doctor is free to accept him as a patient. In certain circumstances, even when the patient is not under active treatment, the doctor will wish to consult that patient's usual medical practitioner in accordance with good medical practice; such consultation must have the consent of the patient. When the doctor undertakes the care of the patient he must accept the responsibility of continuing care, including the issue of any necessary prescriptions.

(b) A medical practitioner with special skills such as acupuncture or hypnosis who is approached by patients for whom he is no the usual medical practitioner is, in the view of the Council, acting in a "specialist" role. He should not, therefore, accept a patient without a reference from the patient's usual medical practitioner, except in those exceptional circumstances laid down in the Association's Handbook of Medical Ethics. another doctor are required to assess or being considered by the Central Ethical
(21.11) Revisions to the Handbook of

monitor the effects of treatment, the responsibility for the decision on the duration or continuation of treatment must lie with the practitioner who initiated the treatment, unless the responsibility for this has been specifically accepted by another doctor.

\section{Advertising and publicity}

(21.7) The concern of doctors about the increasing exposure of colleagues in the press and on radio and television has been brought to the Council's attention. The Council therefore wishes to remind the profession of the general principles expressed in the report on advertising and the medical profession approved by the Representative Body in 1968 and updated in 1974 (appendix II).

\section{Cosmetic surgery}

(21.8) The General Medical Council (GMC) has included a section on "Principles governing the reference of patients to, and their acceptance by, doctors providing specialist service" in its booklet Professional Conduct and Discipline: Fitness to Practise. This should help to resolve some of the problems which have arisen through direct access of patients to cosmetic surgery clinics. The Council has welcomed the GMC statement that general practitioners have a duty "to educate their patients to an understanding of the centra position of their primary role, and also to consider carefully any request by a patien for a specialist opinion even if the general practitioner is not convinced that such consultation is necessary." In considering the proposal for a formal training procedure in cosmetic surgery the Joint Committee for Higher Surgical Training concluded that cosmetic surgery was neither a specialty in its own right nor a subspecialty of plastic surgery.

\section{In-vitro fertilisation}

(21.9) The Council has agreed that a working party be set up to review the present position and the future implications of the work being carried out on in-vitro fertilisation. Its membership and terms of reference have not yet been agreed.

\section{School medical records}

(21.10) The handling of, and access to, school medical records has been carefully Committee and the Central Committee for Community Medicine. It has been agreed that the school medical officer is responsible for the confidentiality of school medical records. Information for school staff must be in the form of a report giving advice on the needs of children who are ill or disabled. Clinical information should not be disclosed unless the prior consent of the parent or guardian has been obtained.

\section{Handbook of Medical Ethics} considered by both the Central Ethical 
Committee, and it is anticipated that a new edition will be published towards the end of 1982. Meantime, the Council has approved additional guidance on ( $i$ ) a doctor's responsibility for treatment (see paras 21.5 and 21.6) and (ii) notification of availability for medical work (available on application to the Secretary).

\section{Manpower}

(22.1) The Council has considered the Social Services Committee's Report on medical education (Short Report) and prepared a detailed response to its recommendations (appendix III).

(22.2) The Council continues to be concerned about medical unemployment generally, and in particular among junior doctors. Its Permanent Committee on Manpower is collaborating with the HJSC on a survey to gauge the extent of medical unemployment among junior doctors. Two thousand junior doctors are being sent questionnaire forms about their careers since qualification.

(22.3) The Council has examined the problems of overseas doctors again and is concerned to try to find a way of helping and developing the careers of those overseas doctors who have spent years in the registrar and SHO grades. It is hoped that the GMC's recently introduced regulations governing limited registration will help future overseas doctors coming to this country so that they gain the maximum benefit from the training here. The Council also believes that the new GMC recommendations on the sponsorship of overseas doctors must be used effectively so that those overseas doctors who do come to the UK spend their time here in approved training jobs.

\section{Scotland, Wales, and Northern Ireland}

\section{Scotland}

Structure and management of the NHS in Scotland

(23.1) At the time of writing, a circular from the Scottish Home and Health Department is awaited on the structure and management of the reorganised NHS. The new structure is likely to come into being on 1 July 1982.

(23.2) In 1981 representatives of the Association met the Chief Medical Officer to discuss medical advice and management within the Scottish Health Service. After these discussions the CMO issued a consultative paper which closely followed the Association's advice. A further paper was expected from the SHHD in early spring.

\section{University finance: effects of UGC cuts}

(23.3) The profession in Scotland is especially concerned at the effects that the cuts in UGC grants to universities will have on the Scottish Health Service, since in Scotland a far higher proportion of patient care within the NHS is provided by doctors employed by the universities than is the case in England and Wales. There is also considerable concern at the effects of the cuts on medical education and on the specialised services formerly provided by the universities.

(23.4) The Government has, to some extent, recognised that Scotland is in a special position and in December 1981 the Secretary of State for Scotland announced that the NHS would fund the replacement of posts cut in university medical schools which were "essential to the maintenance of standards of NHS patient care or to the output of trained specialists." The Association, however, does not consider that this statement goes far enough and it overlooks the effects of the cuts on medical education.

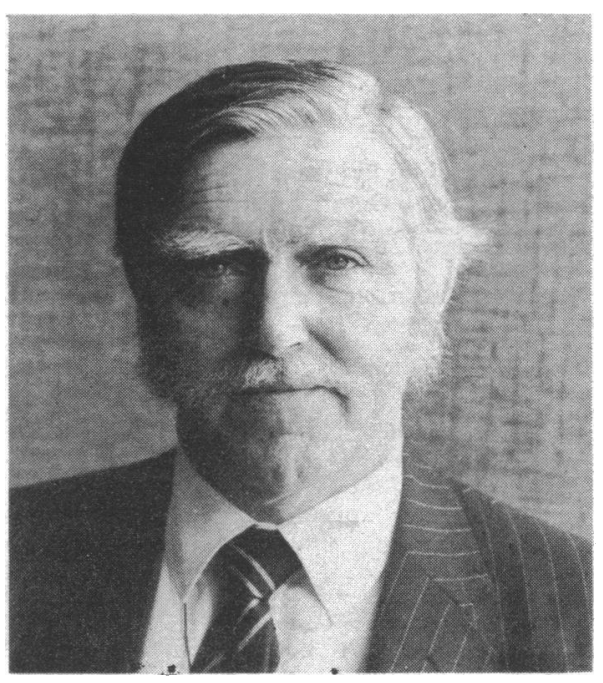

Dr Samual McKechnie, chairman of the Scottish Council.

(23.5) In February 1982 representatives of the Association discussed the matter with the Scottish Minister for Health and Social Work, who said that his Department realised the effects the cuts could have on training of doctors and that it would do everything in its power to mitigate them. In the late summer there would be a second round of consultation on the posts to be replaced within the NHS and the Minister assured the delegation that these extra posts would be funded without reducing the $1982-3$ revenue available to health boards.

\section{Fourth Report of the Social Services Committee on Medical Education (Short Report)}

(23.6) In general Scotland supports the recommendations of the Short Report. It does not, however, agree with those recommendations on medical school intake, and on the extension of the function of the GMC into areas which are properly the responsibility of the royal colleges.

(23.7) The Scottish Hospital Junior Staff Committee has informed the Minister for Health that it supports the Short recommendations and requests that all junior doctors' contracts in Scotland should be held at health board level.
Organisation and management of scientific services

(23.8) There are still problems in the Fife Area Laboratory; the union, ASTMS, is in dispute with the Fife Health Board over management arrangements proposed by the board in February 1981. These arrangements stipulate that the head of department must be a consultant or a top-grade (Whitley scale A) scientist, and have been fully approved by the BMA.

(23.9) It is hoped that the problems in the Forth Valley Laboratory Service have been solved after an agreement between the BMA and the Forth Valley Health Board in January 1982 on the job description for heads of departments. This agreement followed 19 months of wrangling over job descriptions among the technicians' unions, the health board, and the BMA. The new job description for heads of departments clearly shows the responsibility of the head of department for the scientific work of the departments, for departmental work policies, and for the departmental budget and makes it clear that the senior chief MLSOs are accountable to heads of department.

(23.10) In November 1981 representatives of the BMA met the Scottish Minister for Health and Social Work to discuss the continuing problem of the management of scientific services. The minister was unwilling to issue a circular of guidance in Scotland; he did, however, confirm the statement made by his predecessor to the House of Commons on 12 November 1980 that laboratories must be managed by consultants or top-grade scientists and he undertook to reaffirm this policy at the next meeting of health board chairmen.

\section{Health Service complaints procedure}

(23.11) The arrangements for obtaining second opinions in the new complaints procedure, as outlined in SHHD circular No 1981(GEN)43, have been discussed by the Scottish Committee for Hospital Medical Services. In Scotland the chairman of the Scottish Joint Consultants Committee would be asked to nominate two consultants. One nomination would be sought from the appropriate college or faculty and the other from the SCHMS.

\section{Health board assistance to local} authorities by provision of medical services

(23.12) After three years of pressure by the Association on the SHHD and discussions with the Convention of Scottish Local Authorities a circular has at last been issued by the SHHD. This places responsibility on health boards for identifying the services required by local authorities, and the new procedures operate from 1 April 1982.

(23.13) Although fees for these services are not yet under discussion, it is hoped that national agreement on levels of fees will be forthcoming when the services have been identified throughout Scotland.

\section{Health Service cuts}

(23.14) During the session the SHJSC 
has continued to campaign against further Health Service cuts. Scottish junior doctors were particularly concerned at the failure of health boards to redistribute posts which had been removed and, moreover, there has been failure to obtain assurances from health authorities that posts will be redistributed. The SHJSC is seeking the support of the SCHMS for a joint approach to the Scottish Home and Health Department to discuss the problem.

\section{Medical manpower: increase in} applications for vacancies

(23.15) During the past year the SHJSC has received information which indicates that there has been a significant increase in applications for posts throughout Scotland. It is seeking more accurate statistical returns with the help and co-operation of health boards throughout Scotland so that it may continue to monitor the position.

\section{Preregistration house officers in accident} and emergency departments

(23.16) After representations made by the SHJSC, through its representatives on the Scottish Joint Consultants Committee, the Scottish Home and Health Department finally produced NHS Circular No 1981(GEN)33, which lays down revised guidelines for the employment of preregistration house officers in accident and emergency departments. The operative date for the circular is 1 August 1982 From that date no preregistration house officer post will be incorporated within the medical staffing establishment of accident and emergency departments. Preregistration house officers will be able to undergo a period of experience in an accident and emergency department only if the conditions described in the circular are strictly fulfilled.

(23.17) Although the SHJSC welcomes many of the provisions of the revised circular, there has still been some concern at the legal position of preregistration house officers who may be required to undertake duties without adequate supervision. The medical defence organisations are of the opinion that their members' liability would be mitigated in the

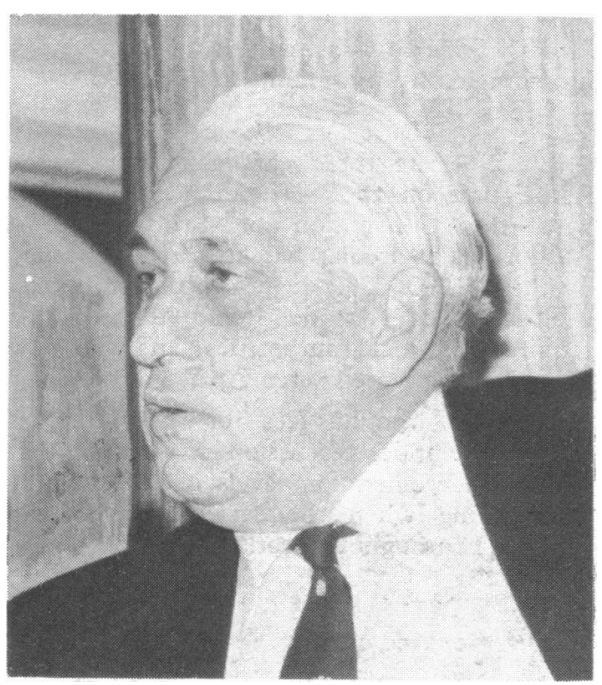

Chairman of the Welsh Council, Mr R H B Mills. event of preregistration house officers being employed in an accident and emergency department without direct supervision.

\section{General practice}

(23.18) The Scottish General Medical Services Committee has discussed with the Scottish Home and Health Department the possibility of closing the "responsibility gap" wherein a principal is not responsible for the actions of his deputy (not on the Medical List), the deputy's staff, or the staff of a deputising service. The committee accepts that a principal should be responsible for the acts of his deputy but does not accept the department's proposals in relation to a deputy's staff or the staff of a deputising service. An approach is being made by the DHSS to the GMSC (UK) in similar terms and the committee awaits the outcome of negotiations at UK level.

(23.19) After lengthy discussions and consultation at local level, the Scottish GMSC agreed to revised arrangements for the distribution of the Scottish Rural Practices Fund. The revised arrangements, which came into effect on 1 October 1981, are intended to give greater recognition to general practitioners in remote areas with widespread country practices. Those general practitioners presently receiving $£ 100$ or less from this source will cease to be eligible.

(23.20) The Scottish GMSC made representations to the Scottish Home and Health Department about the use of a health board's computer records to ascertain whether or not signatories to a petition were registered for contraceptive services. In the committee's view this was a totally improper use of confidential information. The SHHD has since issued guidelines to health boards advising against misuse of, and stressing the need for care in the use of, such records.

\section{Community medicine}

(23.21) The Scottish Committee for Community Medicine has made representations to the Scottish Home and Health Department that, pending national agreement, the SCMO and CMO scale of remuneration be applied to doctors working part time in the NHS Occupational Health Service.

(23.22) The SCCM has made representation to the CCHMS that senior CAMOs, by virtue of the work they perform, be equated with RMOs rather than with AMOs in England, and that in the event of RMOs in England being allowed to retain their salary supplements on receipt of a merit award so should CAMOs in Scotland. The SCCM has the support of the Scottish Council and the SCHMS in this matter.

\section{Wales}

\section{New Welsh Secretary}

(24.1) The Welsh Council has been pleased to welcome Dr Roger Doherty, who has recently taken up his duties as Welsh Secretary. Dr Doherty is, of course, based at the Association's offices in Cardiff but he is trying to visit all parts of the principality and will campaign hard to attract new members.

\section{Reorganisation of the NHS}

(24.2) The Welsh Council considered the consultative document Medical Advice and Management in Wales and submitted detailed comments to the Welsh Office. It welcomed the inclusion of the district medical committee as the body to be consulted about the nomination of the two clinical members of the DHA but regretted that the recommendation of the Chief Medical Officer's working party, that the district medical committee should be the sole nominating body, had not been accepted.

(24.3) After a meeting with the Parliamentary Under Secretary of State for Wales, comments on other aspects of the consultative document, which had given the Welsh Council cause for concern, were accepted by the minister and published in the Welsh Office circular. Medical members of health authorities would ordinarily be in active clinical practice and would reside or work in the district of their authority. The district team of officers would comprise the chief administrator, the chief administrative medical officer, the chief administrative nursing officer, the district treasurer, a hospital consultant, and a family practitioner. The district medical committee would make provision for representation of community health doctors.

(24.4) Representations made to the minister on the difficulties that might occur if one unit medical representative (UMR) was appointed to represent the interests and views of all his colleagues at the unit level resulted in the provision of a linkman to advise the UMR on the branches of the profession with which he might not be familiar, for example, if the UMR was a hospital consultant, a general practitioner linkman would be appointed automatically. The circular states that in special circumstances there may be a need for two UMRs, and the Welsh Council agreed that wherever possible the profession should press for a representative from both hospital and general practice. The Welsh Council considers that as much will depend on the way in which units are established (whether on a specialty, geographical, or functional basis) the district medical committee, as the body defined by statute as being representative of doctors in the district, should resolve the problem of appointing the UMR in the first instance.

\section{Northern Ireland}

Structure and management of the health and personal social services

(25.1) The Northern Ireland Council has received the report prepared by the Depart-

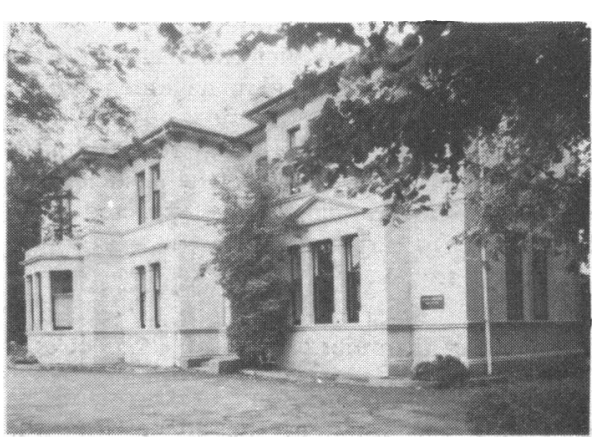

Northern Ireland House, Belfast.

\section{.}

\section{.} . . . . . . 
ment of Health and Social Services, Medical Participation and Advice in the Management of the Health and Personal Social Services in Northern Ireland. Discussion documents have since been prepared by the Northern, Southern, Eastern, and Western Health and Social Services Boards outlining the possible management arrangements for such a structure within the boards and these are now under consideration by the Council.

\section{Medical manpower}

(25.2) The increased output of medical graduates from Queen's University is being studied by the Northern Ireland Council, which has set up an ad hoc committee to look into the matter in relation to career grade requirements-for example, replacements, new posts created, and growth.

\section{Facilities at BMA House}

(25.3) The Northern Ireland Hospital Junior Staff Committee had suggested that BMA House in Belfast should be developed in a social context and that bar facilities should be available. The Northern Ireland Council sought the views of members in the province by means of a questionnaire. There was little support for the proposal that a bar be provided and the Council has therefore not taken the matter further.

\section{Recruitment}

(25.4) There has been an increase in the BMA membership in Northern Ireland from $55 \%$ to just over $58 \%$ as at 31 December 1981 . A further increase is expected following a personal letter to non-members from the chairman of the Northern Ireland Council.

\section{The BMA's publications}

\section{British Medical Journal}

(26.1) Any report on activities at the $B M Y$ seems to start off with an economic appraisal and the current report will be no exception. Although the BMF Publishing Group had forecast a small profit for 1981 , in the autumn it looked as though there would be a small loss. The final accounts, however, showed a very small profit, of under $£ 1000$, achieved despite having to provide an additional unanticipated 4000 copies of the $B M F$ every week to new members as a result of the BMA's increased membership.

(26.2) Paradoxically, the more successful the recruitment exercise of the BMA the more cost falls on the $B M F$, which continues to provide all members with a copy at no cost to the BMA. The financial result also illustrates the need for continual efforts to cope not only with inflation but also with the unexpected, for example, fluctuating dollar exchange rates. Such efforts started some years ago when staff was cut, offices were shared, and a policy of encouraging shorter articles was introduced. They continued last year with the introduction of the "split run" principle but, despite all

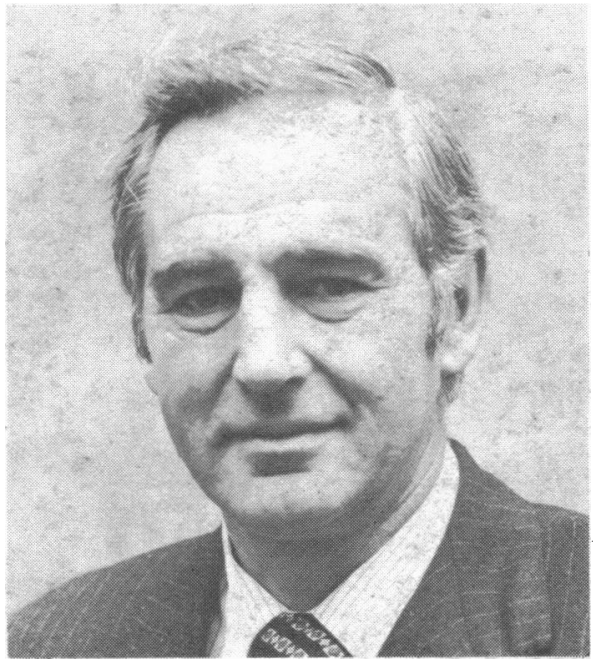

years continue to sell successfully-in particular, The First Year of Life, How to Do It, and Statistics at Square One.

\section{BMA News Review}

(27.1) The year has not been an easy one but, despite economic pressure, $B M A$ News Review continues to return a profit on its activities and to maintain a high position in the readership table among publications for doctors. In 1981,470 pages of advertising were carried, bringing in a revenue of $£ 404780$, resulting in an estimated surplus of $£ 34862$ representing an after-tax profit of $£ 16734$.

(27.2) The circulation of $B M A$ News Review for 1981 has been audited by the Audit Bureau of Circulation at 62483 copies a month.

Mr C J H Logan, chairman of the Northern Ireland Council.

these measures, the Publishing Group barely broke even. To ensure that there could be no loss this year the solution adopted was to recommend that the "compact" edition, which has no advertisements and is sent to overseas and associate members, be sent to retired members, a move that was endorsed by the Council.

(26.3) The response to this introduction has been largely enthusiastic, but some correspondents pointed out that, given they were still undertaking occasional employment, they needed the advertisements for the locum posts. These are available free of charge from the Publishing Department for five weeks, and are also displayed on the $B M F$ Glaxo "Prestel" service, but members doing such jobs who need the advertisements every week may readily obtain them by paying the $£_{50}$ subscription (provided their total annual earnings are less than $f^{8070}$ ). Regrettably, a compact edition cannot be provided with the "Practice Observed" articles in larger size type, but subsidised hand lenses are still available or for $£ 10$ a reader can subscribe to the library service of a complete set of largerprint pages, sent every month.

(26.4) Despite all these safeguards, the Council recognises that a very few readers will feel aggrieved but hopes that they appreciate the cogent reasons for the move. It now costs the $B M \mathcal{F}$ twice as much to supply every member with a full edition, compared with the cost of the compact version; and without such savings the $B M F$ would soon be in serious financial straits.

(26.5) Despite some preoccupation with financial details, the journal has continued to publish old, popular features as well as introducing some new ones. It has also changed its policy on unsigned editorials : most editorials are now signed by the author(s). The new features have included articles on dealing with the disadvantaged, statistics in question, medicine and the bomb, alcohol and alcoholism, Treatment" and "ABC" series have continued, as have "Letter from Chicago" and "USSR Letter," as well as features on spring and autumn books. As usual some series have been collected together and published as books; these include Procedures in Practice, Today's Treatment 4, $A B C$ of $E N T$, and $A B C$ of Hypertension. Booklets published in previous

\section{Family Doctor Publications}

(28.1) The aim of Family Doctor Publications continues to be that of publishing free and low-cost health education material in a readable and authoritative form, a service appreciated by both the public and the profession.

(28.2) New titles in the Family Doctor Booklets range include Father-to-Be, Your Menopause Questions, Women Only, Is Your Medicine Really Necessary? and Health on Holiday. There are now 41 titles in the series, of which 10 were updated in 1981. Although the recession has reduced the demand for the booklets, sales remain sufficiently brisk to cover costs.

(28.3) The four "give-away" titles, You and Your Baby parts I and II, First Baby, and Getting Married, were each revised and reprinted during 1981. The continuing co-operation of the profession in distributing these titles is much appreciated. Specially bound copies of You and Your Baby and the appropriate Family Doctor booklets, including Father-to- $B e$, were sent to HRH The Princess of Wales, who responded with a warm letter of thanks.

(28.4) Following the decision of the ARM 1981 that Family Doctor Publications should be more widely advertised, additional promotion has been put in hand, including some advertising and mailings to health authorities. Chemists have been asked to encourage sales by providing better displays of the booklets. The most effective publicity, however, still arises from the huge amount of media interest generated by each new booklet and advertising in our main publications.

(28.5) In spite of the rising costs of printing, paper, and postage, the Family Doctor Unit conducted its operations at no cost to the Association, with an estimated surplus of $£ 100771$, representing an after-tax profit of approximately $£ 50300$, an increase over the budget of $£ 26884$. This is the best result in recent years.

\section{Charities}

(29.1) The trustees of the Dain Fund have considered the general question of applications for assistance with educational 
expenses incurred by the children of practising doctors who wish to read for a second degree. The trustees have agreed that they will only consider applications where there are unusual or extenuating circumstances. As usual the secretariat will continue to make a preliminary assessment of all the cases referred to the trustees.

(29.2) The trustees of the Sir Charles Hastings and Christine Murrell Funds approved grants amounting to $£ 5750$ in the year ending 31 December 1981. The figure for the year ending 31 December 1980 was $£ 3500$. One grant of $£ 4000$ was awarded from the Louisa Adcock Bequest and $£ 3000$ was later refunded to the Bequest. The BMA Charities Trust Fund disbursed $£ 10000$ to the Royal Medical Foundation of Epsom College. The Dain Fund's financial year ends on 30 April, but in the year ending 31 December 1981 the trustees approved grants and loans amounting to $£ 24155$.

\section{Finances of the Association}

(30.1) The financial statement for 1981 is set out in appendix IV and the budget for 1982 in appendix V. As a result of exacting control over expenditure there was a surplus on all activities of $£ 265620$ (1980-deficit $£ 391$ 946).

(30.2) Information for 1981 provided under the Companies Act 1967 shows that the average number of employees per week was 436 and aggregate remuneration paid to employees was $£ 3362126$. The value of exports was $£ 2432959$ (excluding overseas membership subscription $£ 405800$ ). In the opinion of the Council the market value of the freehold premises is very substantially in excess of the book value but no valuation has been made because of costs.

\section{Standard rate of subscription}

(30.3) The additional income generated by the increase in membership has enabled the Council to maintain and develop regional services in line with the decisions of the Representative Body. As there has been no increase in the subscription in 1982 expenditure has had to be pruned, but there should be a modest surplus at the end of the year.

(30.4) Nevertheless, the Council finds it necessary to recommend an increase in the subscription rate for 1983 . The minimum increase in subscription for 1983 to allow a break-even position in that year is estimated to be of the order of $10 \%$. An increase of $20 \%$, to $£ 120$ a year, would permit further expansion of BMA activities in line with the wishes of the Representative Body and would enable a start to be made on building up the Association's reserves, which have fallen in recent years to a dangerously low level.

Recommendation: That the standard rate of subscription be increased to $£ 120$ from 1 January 1983, and that the following reduction be applied to certain categories:

Reduction

1st calendar year after qualification $\quad 75 \%$

Recommended rate $=£ 30$

Current rate $=£ 25$

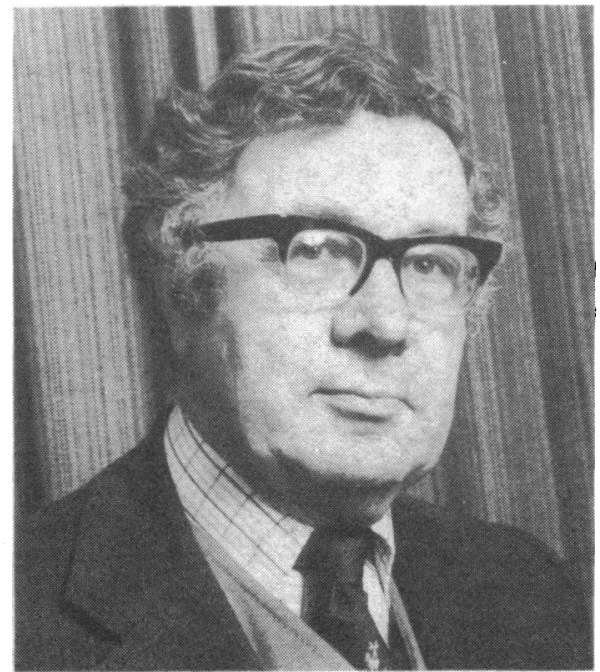

The Treasurer, Dr R A Keable-Elliott.

2nd, 3rd, and 4th calendar years after qualification (but see note 2 )

Recommended rate $=£ 60$

Current rate $=£ 50$ (2nd, 3rd and 4th years)

5 th, 6th, and 7th calendar years after qualification (but see note 2 )

Recommended rate $=£ 90$

Current rate $=£ 75$

Members in the armed Forces except those within one calendar year of qualification

Recommended rate $=£ 90$

Current rate $=£ 75$

Overseas

Recommended rate $=£ 60$

Current rate $=£ 50$

Preclinical teachers and non-

clinical research workers

Recommended rate $=£ 60$

Current rate $=£ 50$

Members first eligible for the retired rate or after 1 January 1983

Recommended rate $=£ 30$

Spouses of members

Recommended rate $=£ 30$

Current rate $=£ 25$

Notes:

(1) A salary link can be claimed by any member whose annual salary or professional income does not exceed the standard salary of a senior house officer at the second incremental point. This will be fixed at $50 \%$ of the standard rate of subscription.

(2) Members who are principals in general practice will pay the standard subscription $(£ 120)$ irrespective of the year of qualification

\section{Membership and regional services}

(31.1) BMA members in practice have risen to nearly $65 \%$ of the total number of practising doctors. This is a considerable achievement and coincides with the establishment by the BMA of an effective presence in the regions in the form of teams of industrial relations advisory staff, fully equipped to advise members in dealing with their own employment problems and relationships with other staff in the Health Service.

(31.2) Apart from BMA Headquarters in London, the national offices in Scotland, Wales, and Northern Ireland, and the regional office in Glasgow, the BMA has 10 regional offices in England and there are plans for further development. There are 14 industrial relations officers in post and, as soon as funds allow, further appointments will be made so that there is comprehensive cover across the whole country.

(31.3) As part of its policy to provide the best possible service to members at local level the Association has continued to widen its local organisation and to strengthen its divisional structure. The place-of-work accredited representative (POWAR) network was established to provide a link between the individual member and the regional service teams. The POWAR is the first point of contact for the member who requires advice. To date 532 POWARs have been appointed.

\section{Personal Services Bureau}

(32.1) There has been a high demand for the bureau's advisory and introductory services this year. The locum section registered 1125 new applicants seeking employment. It received requests from over 1000 general practitioners wishing to employ a locum and it matched prospective locums and GPs on 864 (nearly $81 \%$ ) of these occasions. An additional 652 vacancies were filled in hospitals, an increase of 72 over last year's figures. The partnership introductory service handled a total of 113 vacancies.

\section{Organisation}

\section{NHS reorganisation and division} boundaries

(33.1) From 1 April 1982, 199 districts and single-district areas have been replaced by 194 districts in England. The changes in Scotland, Wales, and Northern Ireland will be of a much smaller nature. It is the policy of the Representative Body that division boundaries should, as far as practicable, be conterminous with NHS boundaries. Divisions have been asked to consider changing their boundaries (where necessary) so that they may conform with those of the new districts. The Organisation Committee has been authorised by Council to approve any changes, but in the vast majority of cases no change has been needed.

\section{Election of representatives to the ARM}

(33.2) The disappearance of NHS areas on 1 April this year will affect the arrangements for electing members of the RB from 1983 onwards. Under the existing rules (Bylaws 37-40) divisions elect ARM representatives after the division or divisions in each NHS area have formed a constituency. The 
constitiency is entitled to elect between one and six representatives according to the number of divisions in the area and in all but single-division areas there are requirements to be met on the professional category of the representatives. The Council believes that, to secure a fair spread of representatives in different branches of medicine, it is essential to retain a method of grouping divisions into constituencies for appointing ARM representatives.

Recommendation: That, with effect from the ARM 1983, Council be authorised to define the constituencies for the purpose of electing representatives of divisions to the Annual Representative Meeting; and that the necessary amendments be made to the Articles and Bylaws.

\section{Conduct of the ARM}

(33.3) An experimental ballot of representatives was held during the first morning of last year's ARM to identify those motions on the agenda referring to matters not covered in the Council's Annual Report to which representatives wished to give priority. The ARM 1981 decided that, as the experiment was successful, the ARM standing orders should be amended so that the ballot would be held automatically in future years. As a result of the Representative Body's decision the first morning ballot will replace the former postal ballot.

\section{Representation of minority groups in the} Representative Body

(33.4) Bylaw 41(1) makes provision for the appointment of representatives of minority groups who would otherwise be unrepresented or inadequately represented at the ARM.

Recommendation: That the following minority groups each be invited to appoint a representative to attend the ARM 1982: advisers to the pharmaceutical industry Association of Police Surgeons, prison medical officers, and Civil Service medical officers

\section{Special group for associate members}

(33.5) The Council told the ARM in 1978 that it believed the formation of a special group for associate members would give medical students a better standing in the affairs of the Association and provide a source from which representatives could be drawn for meetings such as the Junior Members Forum. This was supported by the ARM, which allowed the Association's Articles and Bylaws to be amended so that the formation of special groups of members might include associate members. The Council has since established a special group for associate members, in accordance with the rules for the government of groups approved by the Council in October 1973 , except that membership of the group is limited to associate members.

\section{Special group for Civil Service medical officers}

(33.6) A petition was received from 25 members of the medical staff of the Social Security Division of the DHSS for the formation of a special group for those medical staff. The publication of a notice about this petition in the British Medical fournal stimulated great interest among other medical officers employed by the DHSS and a number of prison medical officers. After discussions with representatives of medical officers employed in the DHSS the Council has established a special group to cover all Civil Service medical officers.

\section{Participation of junior doctors in the} divisional structure

(33.7) The Council continues to be concerned about the difficulties which junior doctors face in participating in local BMA affairs. It is accepted that, in practice, it is extremely difficult for juniors to play an active part in division activities. Division secretaries have therefore been asked to ensure that their executive committees give particular attention to the problem and to try to hold at least one meeting a year which is of special interest to juniors. In addition, they have been asked to send notices of divisional meetings to the mess presidents of hospitals in their divisions.

\section{Junior Members Forum}

(33.8) The 1982 Forum was held at the Worcester College of Higher Education on 3 and 4 April. The subject of the symposium on the first day was "Medical unemploymentspectre or fact ?" and the list of speakers included Mrs Renée Short, chairman of the House of Commons Social Services Committee which recently reported on medical education. On the first evening a successful dinner was held with members of the Worcester and Bromsgrove Division and, as this was the 25 th meeting of the forum, past chairmen were also invited.

\section{Constitution of the Medical Academic Staff Committee}

(33.9) The Council supports a proposa from the Medical Academic Staff Committee that the committee should be given power to co-opt up to three additional members. However, the Council feels that the presen constitution of MASC is unsatisfactory and is proposing to undertake a full review next session.

Recommendation: That the constitution of the Medical Academic Staff Committee be amended by giving it power to co-opt up to three members, in order to secure the representation of all groups of full-time medical academic staff.

\section{Constitution of the Central Committee} for Community Medicine

(33.10) Last year the constitution of the CCCM was amended to include the chairmen of the Scottish Committee for Community Medicine and the Welsh Committee for Community Medical Services, but without voting rights. Representations have been made to the CCCM for these two ex-officio members to be granted full voting rights and the Council supports such a change.

Recommendation: That the chairmen of the Scottish Committee for Community Medicine and the Welsh Committee for
Community Medical Services be given voting rights at meetings of the CCCM.

\section{Charles Hastings Wine Club}

(33.11) There has been criticism from several quarters in recent months about the functioning of the wine club. However, the Council is pleased to report that the Wine Club Committee has undertaken a full review of its arrangements and new suppliers were appointed on 1 February 1982. The Wine Club Committee feels certain that the new suppliers will reactivate the club. In view of the action which has been taken, the Council is satisfied that the wine club should continue in its present form. It will, however, keep the situation under review.

\section{Membership}

(33.12) The Council is encouraged by the continuing increase in the number of associate members. The number at the end of 1981 was 6237 , an increase of 906 on the previous year.

Membership by professional category at 31 December 1981 was as follows:

General practice .. $\quad \ldots \quad \ldots \quad$. $\quad 18994$

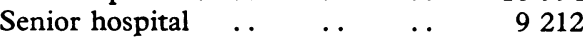

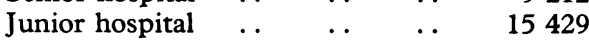

Community medicine .. .. 2001

$\begin{array}{lllll}\text { Civil Service } & \ldots & \ldots & \ldots & 367\end{array}$

$\begin{array}{lllll}\text { Armed Forces } & \ldots & \ldots & \ldots & 367\end{array}$

Occupational health $\quad \ldots \quad \ldots . \quad \ldots 58$

$\begin{array}{lllll}\text { Academic staff } & \ldots & \ldots & \ldots & 1677\end{array}$

In practice, but not identifiable by

group $\ldots$

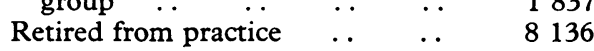

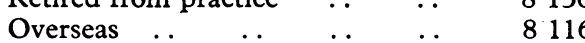

Total

66906

\section{Articles and Bylaws}

(33.13) After the revision approved at the ARM 1981 the Articles and Bylaws were reprinted in loose-leaf form. Thus amendments can be notified on replacement pages. The revised edition has, however, produced problems in relation to ethical complaints, and the necessary amendments, along with other minor changes, appear in appendix VI. The amendments also take account of decisions taken by the Council in connection with the appointment and dismissal of official staff.

Recommendation: That, subject to any amendments arising out of decisions of the meeting, the Articles, Bylaws, and Schedules to the Bylaws be amended in the manner shown in appendix VI and that Council be instructed to submit amendments to the Articles to the Annual General Meeting of the Association.

\section{General Medical Council}

Sponsorship scheme for GMC election 1984

(34.1) It is currently BMA policy (SRM 1975) that the Association should sponsor candidates for $100 \%$ of the directly elected places on the General Medical Council, and 
that an appropriate scheme should be devised to ensure proper representation of the profession as a whole and of young doctors in particular. The long list of candidates for the 1979 GMC election, the low poll, and the comparatively low success rate of BMA candidates led to a suggestion that the $B M A$ should not sponsor all the elected places on the GMC next time, but the Council believes that a stronger BMA presence in the GMC for its 1984-9 session is of considerable importance. The Association should therefore continue to sponsor candidates for all the elected places (39 in England, six in Scotland, three in Wales, and two in Northern Ireland).

(34.2) It has also been suggested that the GMC should conduct its election on a regional basis in the English constituency and that the whole GMC should not come up for election once every five years but that one-fifth of the membership should come up for election every year. While there might be merit in these suggestions they are statute-barred by the Medical Act 1978 and it would need amending legislation to get such changes made. The Government would be unlikely to introduce such legislation before the 1984 GMC election and the Association must therefore devise a sponsorship scheme based on the present election arrangements.

(34.3) A study of the voting pattern in the 1979 election indicates that although the poll in England was only about $30 \%$ of the electorate the membership of smaller sectional medical organisations voted in accordance with lists prepared by their executive bodies and made full use of the preference order which is essential in the single transferable voting system. If BMA members had exerted similar self-discipline the outcome of the election would have been very different.

(34.4) Traditionally, the selection of BMAsponsored candidates has been made by the Representative Body, but after the experience gained at the last GMC election the Council believes that greater emphasis in choosing candidates to be sponsored should rest with ordinary members, on a territorial basis. This is realistic, for-unlike other Association affairs-election to the GMC rests not in the hands of those deeply involved in BMA affairs but in those of the large silent majority who normally take little or no direct part in those affairs. It is their votes (or, as in 1979, their failure to vote) which determine the outcome.

(34.5) The Council proposes that in England the sponsorship scheme for 1984 should be based on peripheral and central selection. It proposes that for England, with the Channel Islands and Isle of Man, 28 candidates should be selected by geographically grouped members (first), and that 11 be subsequently selected by the Council (on advice of committees), to include candidates of background or crafts otherwise not chosen peripherally, and to enable backing to be given to well-qualified candidates who may fail to secure peripheral places.

(34.6) At the appropriate time nominations of candidates for sponsorship would be invited from BMA divisions in England and peripheral craft units. Nominations would also be accepted from any six BMA members in any one geographical group. The nominations received (nominees to be BMA members) for each geographical group would be published as a ballot paper in, for example, $B M A$ News
Review. Voters (who would be assured of total confidentiality but required to give their BMA membership number to exclude voting by non-members) would be asked (i) to mark some or all of the names for their own geographical group with an order of preference as is standard single transferable voting practice and (ii) to mark, if they wished, with an $\mathrm{X}$ names of candidates in any other provinces whom, in the actual GMC election, they would be most likely to wish to support with a fairly high preference. This latter provision is designed to provide guidance to the Council when it, in turn, nominates the last 11 candidates for sponsorship, referred to in paragraph (34.5) above.

(34.7) The selection process would be carried out by single transferable vote. This is the system used by the GMC and would therefore be a valuable educative exercise for the electorate and thus encourage a better response from BMA voters in the GMC election itself.

(34.8) In the cases of Scotland, Wales, and Northern Ireland, where the number of elected places on the GMC is much smaller than in England, the Council proposes that the selection of candidates for BMA sponsorship should be on a national basis from nominations sought from BMA divisions and peripheral craft units. Nominations would also be accepted from any six BMA members in any one country.

(34.9) After the single transferable count of provinces in England, and nationally of Scotland, Wales, and Northern Ireland, the $\mathrm{X}$ count (referred to in paragraph (34.6) above) would be carried out, and with all this information available and bearing in mind such other considerations as might be necessary, the minority of places (11) remaining would be filled by a secret single transferable vote in Council.

(34.10) When the BMA candidates to be sponsored have been selected all the BMA's means of communication must be used to publicise the names of these candidates and to get members to vote in the GMC election and to vote for the BMA-sponsored candidates. A full explanation of single transferable voting will be given with guidance on the way to tackle the voting process.

(34.11) The Council believes that the 1984 GMC election is very important to the BMA and merits time and money being spent on it. It hopes that the proposals outlined above will find favour with the Representative Body. Action will be required in 1983 to seek nominations so that the BMA has a full list of sponsored candidates available early in 1984.

Recommendation: That the scheme put forward for selecting BMA sponsored candidates for the 1984 GMC election be approved.

\section{International affairs}

\section{European Economic Community}

\section{Free movement of doctors}

(35.1) The ARM 1981 reinforced the Association's long-standing policy that all UK nationals fully registered with the General Medical Council should enjoy the right to

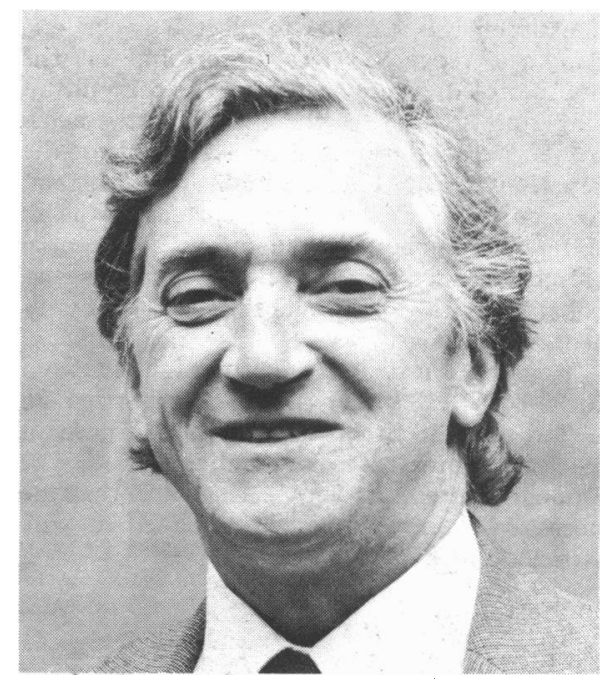

The chairman of the Committee on the EEC, Dr Alan Rowe.

practise freely within the EEC. During the session further efforts have been made to seek implementation of this policy. In the early autumn a delegation from the Association met the then Minister for Health, Dr Gerard Vaughan, proposing a solution to the problem in the form of a Council of Ministers' recommendation to permit UK doctors who had qualified in third countries, that is, countries outside the Common Market, to practise in member States. The Health Minister was sympathetic to the view that the 5000 or so doctors in question should be entitled to benefit under the Medical Directives in the same way as other UK citizens but said that in practice no individual had yet been refused registration in another EEC country because he, or she, held overseas qualifications. The Council has been told by the Health Minister that the matter has been raised in the European Parliament and is currently being considered by the European Commission. The Health Minister had undertaken to discuss with the GMC the reciprocal arrangements which might have to be made, but he is now awaiting clarification of the Commission's attitude before taking further steps.

\section{Standing Committee of Doctors of the EEC}

(35.2) The Association is a member of the Standing Committee of Doctors of the EEC, which has grown with the addition of Greece and awaits the possible addition of Spain and Portugal. The standing committee is looking at ways of streamlining its structure and thus of reducing its running costs, the bulk of which are for translation and interpretation. It has attended a meeting with Commissioner Ivor Richard, one of the new European Commissioners appointed in January 1981. There have been significant changes within the Commission, and Commissioner Richard has become responsible for most matters of interest to the health professions including education and medical research. The United Kingdom delegation to the standing committee has always favoured the concept of a co-ordinated health directorate within the Commission and it is clear that the Association's representations have succeeded so that effectively all health matters are now the 
responsibility of Commissioner Richard, with the exception of the right of establishment, which remains with the commissioner responsible for internal market.

\section{Medical treatment in other member States}

(35.3) The Council is pleased that a meeting of Social Affairs Ministers in Brussels recently agreed that self-employed people and their families from Britain who fall ill in EEC countries will receive medical treatment on the same basis as employed workers. There are an estimated $1.8 \mathrm{~m}$ self-employed people in the UK-of whom 26940 are general practitioner principals-and the change will take effect on 1 July 1982.

\section{General practice directive}

(35.4) After two years of discussion, agreement was finally reached between member States on a draft directive introducing the mutual recognition of training in general practice. The proposal is that general practitioners wishing to practise within the social security system of any member State will have to have completed a minimum of two years' training. The directive must come into force by 1990 , with a review after five years. Thus it will oblige countries without specific training schemes for general practice to start drawing up plans now to introduce them. The firm commitment of the European Commission to finalise the directive this year will go a long way towards maintaining standards of vocational training in the UK.

\section{Specialist training in other EEC countries}

(35.5) The EEC medical directives opened the way for the mutual recognition of medical qualifications, but there has never been a means of recognising periods of specialist training completed in other member States, and this has tended to discourage trainees from moving within the EEC. The European Commission's Advisory Committee on Medical Training has published an opinion which, it is hoped, will make easier the mutual recognition of such periods of training. Specialist trainees will be encouraged to train in other States by the Standing Committee of Doctors which is launching a pilot project. A small number of posts will be identified in each member State for participation in the project. The Council knows that there is a demand for action in this area; the secretariat deals with about 180 inquiries each year from doctors looking at the possibility of movement within Europe and of these a majority are specialist trainees. The Council is, therefore, co-operating with the DHSS and other organisations to promote the scheme.

\section{European Union of Medical Specialists (UEMS)}

(35.6) In October 1981 a meeting was held of the UK's representatives on the monospecialist sections of UEMS. These representatives are nominated jointly by their royal colleges and the BMA to represent their specialty, while the BMA and the JCC nominate a representative each to the UEMS council. Many of the sections have achieved significant progress towards harmonising specialist training schemes in Europe, though others do not function efficiently. The meeting was useful and enabled the representatives to consider how to increase the effectiveness of the UK's contribution to the sections.

\section{SEPLIS (European Secretariat of the Liberal, Independent and Social Professions)}

(35.7) The UK delegation to the Standing Committee has repeatedly warned other member States of the growing influence of SEPLIS, which does not include representatives of the medical profession at European level, nor of any fully representative interprofessional group from the UK. The Council has co-operated closely with the other UK professions, particularly the health professions, on this issue, and the Government, at the request of the health professions, has successfully delayed a decision by the Council of Europe to grant consultative status to SEPLIS. The danger is that SEPLIS may erode the influence exerted by the Standing Committee of Doctors on the EEC Commission if it is consulted on matters affecting all professions and the medical profession in particular. At present the Standing Committee is satisfied that it speaks for the profession at EEC level and the European Commission consults it accordingly.

\section{WMA and CMA}

(36.1) The Council has again considered the Association's continuing membership of the WMA, partly in the light of the admission of the Medical Association of South Africa and partly because of concern over the WMA's constitution. It has decided to seek radical changes in the constitution and believes that the Association should leave the WMA unless the changes are achieved by the 1985 biennial assembly. current year but it is hoped to hold a biennial meeting in Trinidad in early November which will be accompanied by a clinical meeting.
(36.2) The CMA has not met during the

\section{Commonwealth and International Medical Advisory Bureau}

(37.1) During 1981 just under 2000 doctors made initial inquiries of the bureau, of which 600 were United Kingdom doctors inquiring about visits and work in other parts of the world. The number of inquiries about prospects abroad was slightly reduced during 1981, which may indicate the effect of increasing restrictions on immigration imposed by several countries. Many members look for short-term employment to fill in a period in between posts, mainly in developing parts of the world, but for those inquiring about longer-term employment Canada has been by far the most popular. Inquiries from overseas doctors continued to be about opportunities for postgraduate study and hospital training.

\section{Medical dispute in Malta}

(37.2) The dispute between the medical profession and the government of Malta has continued. During the year 22 more Maltese students qualified in this country, leaving 16 to qualify in the summer of 1982. The BMA Malta Fund has paid monthly grants to several students to assist in the payment of tuition fees and accommodation. Once the last students, who transferred to a United Kingdom university from the Malta Medical School ill 1977 and 1978, have qualified the fund win cease to exist. Many of the newly qualified doctors and consultants from Malta, now resident in the United Kingdom, hoped that there would be a change of government after the Malta elections in December. But such a change did not come about and it seems that many of them are now content to remain in the United Kingdom.

\section{Vietnamese refugee doctors}

(37.3) There has been no increase in the number of Vietnamese doctors (18) during 1981 , but the availability of medical school places has presented great problems. One Vietnamese doctor has qualified MRCS, LRCP and is undertaking his preregistration year and another has passed the PLAB test but has not

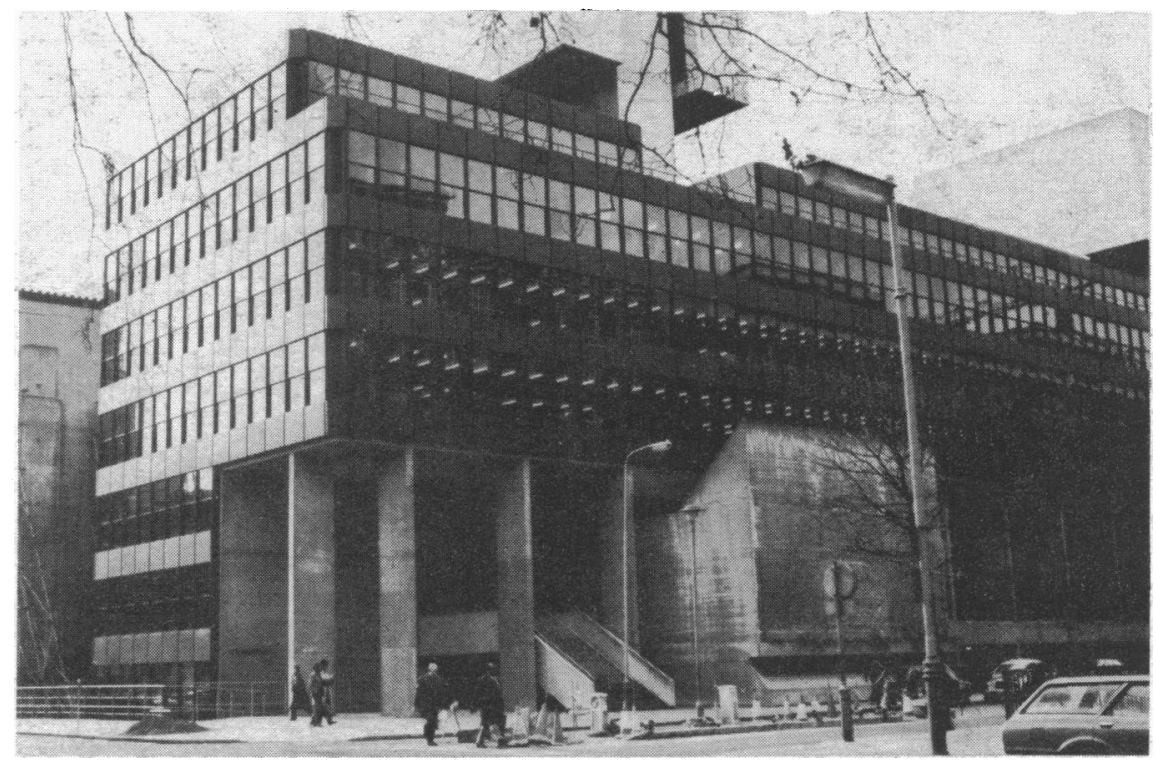

The ARM will be held in the Logan Hall, University of London's Institute of Education. 
yet been successful in obtaining a hospital appointment.

\section{Doctors and social work}

(38.1) The evidence given by the Council to the National Institute of Social Work's (NISW) inquiry into the role and tasks of social workers was generally welcomed. The inquiry is expected to report in May 1982 and its response to the Association's call for a statutory professional regulatory body and for minimum training standards for social workers is awaited.

(38.2) The Council has proposed amendments to section 16 of the Mental Health (Amendment) Bill which would allow for second opinions on emergency admissions to mental hospitals and for responsibility for the refusal to admit to rest with the social services department when the certifying doctor disagrees with the approved social worker. The Department of Health has recently issued draft guidelines for the approval of social workers under the Bill. They propose minimum training standards and a local authority panelcontaining at least one doctor-to approve social workers. Both issues were supported by the Association and by the social workers' professional organisation.

\section{BMA deputising services}

(39.1) The 19 BMA deputising services throughout the country are continuing to operate successfully. The operating company, Air Call Ltd, in consultation with the Central
Advisory Committee, is developing extended rota schemes in smaller areas where deputising services are not viable.

(39.2) A detailed guidance document on procedures to be followed in connection with the discipline and dismissal of deputies working in the BMA Deputising Service has been sent to local medical advisory committees.

(39.3) New guidance has also been prepared for liaison officers, who are responsible for the day-to-day monitoring of the operation of the service in each area, and more comprehensive reports will in future be made available to local medical advisory committees and to the Central Advisory Committee.

(39.4) BMA members who use the services may enter into more advantageous contracts which will save them up to $£ 132$ a year. In addition, the operating company is offering BMA members a $10 \%$ discount on various communications services-for example, paging devices.

\section{Managerial, Professional, and Staff Liaison Group}

(40.1) The MP\&SLG made a substantial impact in Whitehall and Westminster in 1981 and is now consulted on all major issues by central Government. The Secretary of State for Employment gave MP\&SLG the right to make nominations to seats on industrial tribunals, which had previously been open only to the TUC. Appointments were made in proportion to the respective strengths of the two organisations. MP\&SLG also made several successful nominations to the trade union seats on new district health authorities.
(42.0) Meetings have been held with Ministers in the Department of Employment and Trade. The Rt Hon David Steel MP, leader of the Liberal Party, and the Rt Hon Dr David Owen MP have attended MP\&SLG meetings during the year.

\section{Disabled Persons (Employment) Acts}

(41.1) The Association is fully aware of the obligations imposed by the Disabled Persons (Employment) Acts and is doing everything possible to ensure that the Association meets them. It considers sympathetically applications for employment from registered disabled persons and, where job content will allow, provides equal opportunity for training, career development, and promotions. Unfortunately, although it co-operates with the local disablement resettlement office, it does not receive a significant number of applications to cover the legal requirement of $3 \%$ of employers and, therefore, it holds a certificate of exemption issued by the Department of Employment.

\section{Thanks}

(42.1) The Council thanks all those who have worked on the Association's behalf during the session, particularly honorary secretaries of divisions, and POWARs as well as regular committee members and chairmen who give unstintingly of their time on behalf of their colleagues. It also places on record its thanks to and appreciation of the Association's staff at headquarters and in the regions.

\section{APPENDICES}

\section{Appendix I: Council attendances}

\begin{tabular}{|c|c|c|c|c|c|c|c|c|}
\hline & \multicolumn{2}{|c|}{ Attendance } & & \multicolumn{2}{|c|}{ Attendance } & & \multicolumn{2}{|c|}{ Attendance } \\
\hline & Actual & Possible & & Actual & Possible & & Actual & Possible \\
\hline Sir John Walton, Newcastle & & & Dunlop, J M, Hull & 3 & 4 & Miller, J E, Glasgow & 4 & 4 \\
\hline upon Tyne (President) & 4 & 4 & Elliott, A, Ilford & 4 & 4 & Mills, R H B, Merthyr Tydfil & 3 & 3 \\
\hline J H Marks, Elstree (Chairman & & & Ford, J A, Glasgow & 3 & 4 & Mitchell, G M, Cardiff & 4 & 4 \\
\hline of Representative Body) & 4 & 4 & Gilkes, M J, Brighton & 4 & 4 & Moshy, R, Stockport & 4 & 4 \\
\hline A H Grabham, Kettering & & & Goodman, M, Liverpool & 4 & 4 & Nelson, Sir Richard, Burley & 3 & 4 \\
\hline (Chairman of Council) & 4 & 4 & Graham, J C, London & 4 & 4 & Noble, J S, Ashington & 3 & 4 \\
\hline R A Keable-Elliott, & & & Gray, R J, Wimbledon & 1 & 2 & Payne, J P, London & 4 & 4 \\
\hline Stokenchurch (Treasurer) & 4 & -4 & Greenwood, R K, Leicester & 4 & 4 & Quilliam, J P, London & 4 & 4 \\
\hline & & & Hicklin, J A, Crawley & 3 & 4 & Rees, M R, Sheffield & 2 & 4 \\
\hline Alexander, B L, Manchester & 4 & 4 & Hooper, Judith, Langholm & 2 & 4 & Richards, S Jane, Exeter & 4 & 4 \\
\hline Appleyard, W J, Canterbury & 3 & 4 & Horner, J S, Croydon & 4 & 4 & Riddle, W G A, Gateshead & 4 & 4 \\
\hline Ball, J G, Bewdley & 4 & 4 & Howie, Sir James, Edinburgh & 2 & 4 & Ross, A P J, Winchester & 4 & 4 \\
\hline Bolt, D E, Hampton Hill & 4 & 4 & Husain, $M$ Hamid, Rotherham & 3 & 4 & Rowe, A J, Bury St Edmunds & 4 & 4 \\
\hline Burrows, $M$ M, Birkenhead & 4 & 4 & Jenkins, $\mathrm{S}$, Manchester & 4 & 4 & Six, S, Reading & 4 & 4 \\
\hline Cameron, Sir James, Wallington & 3 & 4 & Josse, S E, London & 3 & 3 & Stallworthy, Sir John, Oxford & 4 & 4 \\
\hline Chisholm, J W, Henley-on- & & & Kearns, J L, London & 4 & 4 & Thomas, M J G, Aldershot & 4 & 4 \\
\hline Thames & 4 & 4 & Kielty, P F, Harpenden & 4 & 4 & Tranter, A W, Orpington & 4 & 4 \\
\hline Clark, A A, Dalmuir & 4 & 4 & Kyle, J, Aberdeen & 4 & 4 & Watts, J C, Woodbridge & 2 & 2 \\
\hline Cormack, G, Morpeth & 4 & 4 & Lawrence, R A A R, Derby & 4 & 4 & Wells, C J, Sheffield & 4 & 4 \\
\hline Cove-Smith, $R$, London & 4 & 4 & Lewis, E B, Hythe & 4 & 4 & White, Mary, Bromsgrove & 4 & 4 \\
\hline Crawford, G E, Liverpool & 4 & 4 & Logan, C J H, Belfast & 2 & 4 & Williams, D L, Holywell & 4 & 4 \\
\hline Davidson, W Keith, Glasgow & 1 & 1 & McKechnie, S, Greenock & 3 & 3 & Wilson, J, Whitehead & 4 & 4 \\
\hline Dawkins, Joan StV, & & & Machin, D G, Wirral & 2 & 2 & Wilson, M A, York & 4 & 4 \\
\hline Northampton & 4 & 4 & Mander, A M, London & 3 & 4 & & & \\
\hline
\end{tabular}




\section{Appendix II: Advertising and the medical profession}

\section{The doctor and the general public}

Modern life brings the doctor into contact with the general public in numerous ways, both directly and indirectly, and raises for him problems of conduct unknown to his prede cessors. The general public interest in medica knowledge, the dissemination of medical information through radio and television, and the press interview, all demand the exercise of the utmost caution by the doctor, whose professional standards condemn self-advertisement and publicity. In 1968 the Council drew up a report which was approved by the Representative Body to serve as a guide to the profession, and further amendments were made in 1974.

\section{Report on advertising and the medical profession \\ (Approved by the Representative Body in 1968 and 1974 .}

Attention is drawn to the statement of the General Medical Council on advertising, which appears in the pamphlet issued by the GMC on Professional Discipline. The Association is in agreement with this statement.*

NB Ultimate responsibility in all these matters rests with the individual concerned, but practitioners finding themselves in any difficulty in deciding upon their course of action or in doubt as to the safeguards necessary are advised to seek guidance from the Secretary of the Association.

\section{ADVERTISING}

(1) The word "advertising" in connection with the medical profession must be taken in its broadest sense, to include all those ways by which a person is made publicly known, either by himself or by others without objection on his part, in a manner which can fairly be regarded as for the purpose of obtaining patients or promoting his own professional advantage.

(2) It is generally accepted by the profession that certain customs are so universally practised that it cannot be said that they are for the person's own advantage, as, for instance, a door plate with the simple announcement of the doctor's name and qualifications. Even this, however, may be abused by undue particularity or elaboration.

\section{AVOIDANCE OF PUBLICITY}

(3) Any publicity by or on behalf of or condoned by a doctor which has as its object the personal advertisement of the doctor is highly undesirable, unethical, and in contravention of paragraph viii of Professional Discipline issued by the General Medical Council, Part 11.

* Current advice on advertising, canvassing, and related professional offences is covered in para iv of Part II of the GMC's booklet, Professional Conduct and Discipline and Fitness to Practise.
(4) Therefore no active steps should be taken by any medical practitioner to achieve publicity as a doctor otherwise than as provided below. A doctor should take all possible steps to avoid or prevent publicity where it can be shown to be unnecessary or to be to his advantage as a doctor.

\section{NEWSPAPERS, RADIO, TELEVISION}

(5) The public has a legitimate interest in the advances made in the science and art of medicine, and it is of advantage that medical information discreetly presented should reach the public through such media, both for the general instruction of the inquiring layman and for the particular purpose of "health education."

(6) Great caution is necessary in public discussions on theories and treatment of disease owing to the misleading interpretation that may be put on these by an uninformed public to the subsequent embarrassment of the individual doctor and the patient. Sensational presentation should be avoided at all costs. The discussion of controversial medical matters, particularly in relation to treatment, is more appropriate to medical journals or professional societies.

(7) Medical practitioners who possess the necessary knowledge and talent may properly participate in the presentation and discussion of medical or semimedical topics through such media.

The Representative Body, in 1974, resolved:

"That a clear distinction be made between discussions solely of general principles of medicine, where no objection would be made to the naming of the doctor involved, and those discussions which result in any particular reference by that named doctor to the way in which he approached clinical problems."

(8) Anonymity is particularly important in circumstances where the doctor refers to his personal management of individual clinical matters. The professional tradition of anonymity must continue in this context, in order to avoid any risk of a charge of advertising.

(9) It is important that doctors participating in the presentation and discussion of medical matters through such media should take all steps to avoid laudatory references to their professional attainments and achievements. References to a named doctor being specially skilled in a particular form of treatment or specialty, or in the use of some special apparatus or the performance of some particular operation, are to be avoided wherever possible. It is necessary at all times to observe modesty concerning personal attainments and courtesy in reference to colleagues. Where a doctor's qualifications are given they should not be unduly emphasised-for example, by large or heavy type. In the case of public appearances it is advisable to acquaint the chairman, or interviewer beforehand, of the need to be circumspect in referring to professional status or attainment in any introductory remarks. This is particularly important where the press are likely to be present.

(10) No correspondence with the lay public should be entered into by the doctor as a result of his presentation.

(11) There is a wide range of subjects unrelated, or only remotely related, to the practice of medicine where there may well be no objection to the announcement of the name and usual designation of a doctor who is an authority on the particular subject. But there should be nothing in the announcement or presentation of the subject which could be regarded as promoting his professional advantage.

(12) Presentations or discussions of medical matters through newspapers, periodicals, radio, TV, etc, the transmission of which is restricted to other countries, need not be anonymous even where contributions are frequent, provided that the presentation is not contrary to the rules of the profession in the other countries concerned.

(13) Care should be taken to ensure that privately owned institutions with which the doctor is professionally associated cannot be identified in the course of the presentation whether directly or through accompanying advertisements.

\section{MEDICAL ATTENDANCE UPON ROYALTY AND} OTHER PROMINENT PERSONS

(14) Attendance upon royalty and other prominent persons frequently leads to the mention of doctors' names-for example, in bulletins. This is traditionally accepted as in the public interest and unavoidable.

\section{PRESS INTERVIEWS}

(15) A practitioner should exercise the greatest caution in granting a press interview. A seemingly innocuous remark or casual aside is often open to misinterpretation and may easily form the subject of a damaging headline. This may place the practitioner in a position of embarrassment and danger. In certain circumstances it may be preferable to promise a prepared statement than to give an impromptu interview, or, if an interview be granted, to ask for an opportunity to approve the statement in proof before it is published.

(16) It should be noted that the Association has authorised the appointment of an honorary press secretary in each of the divisions. His duties include the function of acting as a link between the profession and the public, including the press, on behalf of both the division and headquarters, on all matters affecting the profession's relations with the public. His services could be used on all suitable occasions.

\section{CONDONATION OF PUBLICITY IN THE PRESS}

(17) Exception cannot reasonably be taken to publication in the lay press of a doctor's name in connection with a factual report of events of public concern. On occasion, however, in press reports, articles, or social columns, statements are made without previous consent, commenting favourably on the professional activities or success of medical 
practitioners. These statements cannot fail to place the named practitioner in a critical and embarrassing situation, and should not be allowed to pass unchallenged. In every case of this type the medical practitioner involved should send a letter of protest to the editor marked "Not for publication" demanding that statements concerning his professional activities be not published in future without previous personal consent. Statements disclaiming responsibility for offending publicity should not be offered to the lay press for publication.

REPORTS OF SOCIAL OCCASIONS AND GATHERINGS

(18) It is usually unexceptionable for a doctor's name to be included in a report of a social occasion or gathering. The more distinguished a man the more often is his name likely to appear as an important guest at a function. Nevertheless, the name that is always occurring, sometimes in unlikely places, may well be suspect.

It is not beyond the wit of man to manage to appear prominently and frequently in sufficien places for his name to become better known than would be the ordinary sequel of a good professional reputation. Ambition may supersede conscience and modesty.

\section{HOLDING OF PUBLIC OFFICE}

(19) It is the recognised duty of a medical man to take his share as a citizen in public life and to hold public office should he so desire, but it is essential that the holding of public office is not used as a means of advertising himself as a doctor.

\section{COMMUNITY PHYSICIANS}

(20) Publicity is necessary in carrying out the environmental health and certain other duties of community physicians and other medical men who hold posts in the public services. Provided that this is not used for the individual's advancement in his profession it may be rightly allowed.

\section{PHOTOGRAPHS}

(21) A practitioner's photograph appearing in connection with an interview or an article published in the lay press on professional subjects is a most undesirable form of publicity, and every reasonable precaution should be taken to ensure that such photographs are not published.

\section{ADVERTISEMENTS IN THE LAY PRESS}

(22) The use of the advertising columns of the lay press to publicise the professional activities of individual medical practitioners, even in the absence of a name-for example, by using a box number-is unethical. A particularly reprehensible form of advertising of this type is the submission to the press directly or through an agent of information concerning the personal movements, vacation, or new appointments of a medical practitioner for publication in social columns.

\section{EXAMPLE OF SENIOR PRACTITIONERS}

(23) There is a special duty upon practitioners of established position and authority to observe these conditions, for their example must necessarily influence the action of others.

\section{DANGERS}

(24) The particular dangers in each of these fields of activity are referred to in the preceding paragraphs. But in every case the guiding principles should be those of the above mentioned pamphlet issued by the General Medical Council, which lays down that a practitioner should not sanction or acquiesce in anything which commends or directs attention to his professional skill, knowledge, services, or qualifications, or deprecates those of others, or be associated with those who procure or sanction such advertising or publicity.

GENERAL

(25) After making all allowances for all those modes of publicity for which there may be some justification, there remain many instances which can be regarded as contravening the spirit of the above mentioned pamphlet issued by the General Medical Council. The Association is convinced that in taking up the attitude of determined opposition to undesirable methods of publicity it is acting in the best interests of the public as well as of the medical profession. Advertising by the profession in general would certainly destroy those traditions of dignity and self-respect which have helped to give the British medical profession its high status. The Association therefore draws the attention of the profession to the danger of these objectionable methods, and stresses the need for every member of the profession to offer a firm resistance to them.

\section{Appendix III: BMA's response to the Fourth Report of the Social Services Committee on Medical Education}

The Social Services Committee is the latest in a long line of royal commissions, committees, and working parties to study the problems of medical education, manpower, and career structure. Some, like the Social Services Committee, the Royal Commission on Medical Education, and the BMA Council Working Party dealt with the subject as a whole; others have been more selective in their deliberations and recommendations.

The Social Services Committee states in para 62 of its report:

"The linkage which we thus attempt to make between theory and practice, between the requirements of training and the requirements of service, seems to us to be of an importance which has not always been recognised. Estimates of the number of doctors required have often been considered in isolation, withou regard for the crucial impact which the staffing structure makes upon their employment and upon their efficiency."

Its historical survey takes us through all the stages of development of the present situation.

\section{General comment}

As a result of implementation of recommendations from some reports-for example, the Willink Report, to reduce the intake of medical students and 11 years later of the Royal Commission on Medical Education to increase it, and failure to implement others such as the relative expansion rates in the consultant and training grades in the hospital service advised in the Progress Reports of 1969-71, there still exists an imbalance between these grades. Because of the increased intake of medical students and the presence of many doctors from overseas there is a real fear among younger doctors of reduced career prospects and increasing unemployment, particularly among women doctors and doctors from overseas.

The Social Services Committee proposes as a solution a large and rapid increase in hospital consultant posts with, pari passu, reduction in the training grades and in their hours of work. This suggests a failure by the committee fully to understand the reasons why consultants are reluctant to accept such a solution. Those who carry the ultimate responsibility for the medical care of hospital patients require an opportunity to study the implications of such a solution for the quality of patient care and for their own job content, working conditions, and way of life.

Demand for doctors is subject to overall economic conditions, finance available to the NHS and to the private sector, and to changing medical practice. In a time of deep recession and severe limitation of public expenditure it is unrealistic to expect expansion of services and staff. Therefore, it is sensible to limit medical student intake to such numbers as can be economically employed in the NHS where the great majority of doctors practising in the UK spend their working life. Team work in patient care means that many tasks formerly performed by doctors now fall to other health professionals. The profession accepts these changes but sees no advantage to patients in pressing for doctor substitution as a way of 
providing care in the so-called shortage and unpopular specialties.

Maintenance of standards in both undergraduate and postgraduate medical education is the responsibility of the General Medical Council working in conjunction with the universities, royal colleges and faculties, and other bodies responsible for the provision and co-ordination of postgraduate and continuing medical education. The General Medical Council has introduced new arrangements for limited registration for overseas doctors and it will be granted only for supervised employment in hospitals or hospital posts that have been approved for training posts, the royal colleges and faculties having the authority and responsibility for granting such approval, and the employing authorities and consultant staff the duty to ensure that the training content and working conditions necessary for approval are attained and maintained. Any further regulating or advisory bodies in this sphere are unnecessary and undesirable.

Detailed comments on the recommendations of the Social Services Committee are attached.

\section{Recommendations 1 and 2}

Council accepts that it is desirable that a higher proportion of patient care should be provided by hospital doctors in the career grades. However, there are elements in patient care which are within the competence of doctors in the training grades always provided the level of training they have reached is taken into account. Nevertheless, Council believes that consultant advice and supervision should always be readily available when needed or requested by doctors in the training grades and to this end, as well as to improve staffing ratios and career prospects, there should be a change in the ratio of doctors in the training grades to career grades in the hospital service.

It is also the Association's policy (resolution 12 of the ARM 1981): "That in order to improve the standards of patient care, this conference would welcome a balanced expansion of the consultant grade, provided that adequate funding and facilities are available and that the position of existing consultants is safeguarded."

Although there is agreement in principle on the aims of recommendations 1 and 2, there is a difference of emphasis placed by the CCHMS and the HJSC upon the appropriate rate at which the changes should be implemented.

\section{Recommendation 3}

The Annual Representative Meeting 1981 called in resolution 37 for the implementation of the hospital practitioner grade mark II to be started and similar resolutions were passed in 1977 and 1979. This policy is supported by the CCHMS and the GMSC but at the moment it is opposed by the HJSC which believes that it might interfere with the career structure and might introduce a subconsultant grade into the hospital service. However, the Association is emphatic that there should be no subconsultant grade as the following para 8.60 of its evidence to the Royal Commission on the NHS shows:

"One thing is clear, there must not be a subconsultant grade into which would be forced jarge numbers of individuals suitable in respect of training and personality for consultant status, but unable to achieve it because of

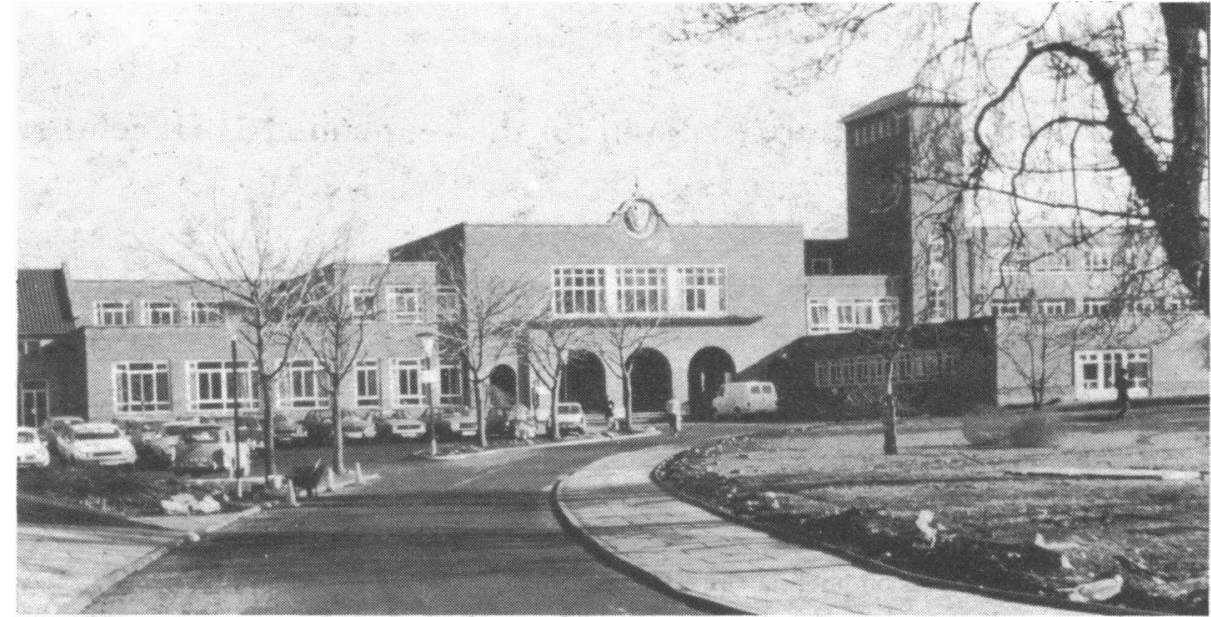

Worcester College of Higher Education, the site of the Hastings Celebration Meeting from 9 to 11 September.

an insufficient establishment of consultant posts relative to those in the training grades. (The 1973 Conference of Representatives of Hospital Medical Staffs resolved 'that this conference reaffirms its opposition to the introduction of an established whole-time subconsultant career grade in the hospital service.') There is no evidence to suggest that any substantial number of the doctors who progress to registrar level and obtain higher qualifications are neither suitable nor anxious to achieve the full responsibility of the consultant. Arbitrarily to deny to some doctors the full development of their abilities through deficiencies of the career structure would be quite indefensible and a poor recipe for a satisfactory NHS."

The evidence was approved at the Special Representative Meeting in 1977.

\section{Recommendation 4}

The Council supports this recommendation provided that associate specialists wishing to return to the mainstream hospital career structure do so in open competition for posts.

\section{Recommendation 5}

The Council supports this recommendation.

\section{Recommendation 6}

The Council has very strong reservations about wider experimentation in doctor substitution. It is unable to recommend support of this proposal until there is clarification and stricter definition of its terms. The Association's policy on multidisciplinary terms is clear. The Council considers that to a large extent the matter in this recommendation is a side issue to the manpower problem.

\section{Recommendation 7}

The Council supports the proper development of the hospital practitioner grade mark I.

\section{Recommendation 8}

The Council agrees that central manpower planning should deal with all branches of the profession in an integrated way but it foresees difficulties if this is done at local level because of the independent contractor status of general practitioners.

\section{Recommendation 9}

The Association has a clear policy on the question of medical school intake which is embodied in the following resolution passed at the ARM 1981 :

"That this meeting strongly endorses Council's view that the student intake of British medical schools should be frozen at the 1979 level until a full assessment of the effect of the rapid increase of this intake has been made, including the financial implications for the NHS, and that Council be instructed to convey to the DHSS and University Grants Committee its continuing concern about the number of medical graduates being produced."

This is a serious matter which must be reexamined because of the economic difficulties and constraints which now face the NHS. Moreover, the question of overseas doctors in the NHS must be reviewed. Medical school intake is intimately related to the numbers of overseas doctors in the National Health Service and the former Council Working Party on Medical Manpower, Staffing and Training Requirements (the Wilson Report) contained the following recommendation $B$ which was approved by the Council at its meeting in October 1979 and endorsed by the Representative Body in 1981 :

"We therefore recommend that regulations be introduced to enable there to be control of the numbers of doctors coming to this country to take up professional appointments and to regulate the period during which they can practise here."

The association cannot, therefore, support recommendation 9 of the Short Report.

\section{Recommendation 10}

The Council believes that if a junior post loses its recognition for training purposes, it should be closed by the health authority. The reviewed to try to correct its defects. After the situation has been most carefully examined and if a service need remains, whenever appro-

continued on page 31 components of the post should then be 
Appendix IV: Financial Statement

Income and Expenditure Account for the year ended 31 December 1981

Income

$\begin{array}{ccc} & 1981 & 1980 \\ \text { Notes } & £ & £\end{array}$

Membership subscriptions

4321185

2995931

Rents

712779

664782

Investments and deposits

322348

262703

Net surplus on publications

3

215069

24906

$£ 5571381$

$£ 3948322$

\section{Expenditure on professional activities}

Secretarial Department

\begin{tabular}{|c|c|c|}
\hline & 1190554 & 1093672 \\
\hline & 303407 & 260367 \\
\hline & 1047139 & 893995 \\
\hline & 83838 & 68433 \\
\hline & 190817 & 163219 \\
\hline & 128956 & 111957 \\
\hline & 38998 & 32704 \\
\hline & 61356 & 60871 \\
\hline & 167724 & 156878 \\
\hline & 72917 & 62699 \\
\hline & 57556 & 53806 \\
\hline & 69656 & 71812 \\
\hline 9 & 326560 & 134947 \\
\hline & 228933 & 212631 \\
\hline 6 and 7 & 787632 & 643426 \\
\hline & $£ 4756043$ & $£ 4021417$ \\
\hline & 815338 & $(73095)$ \\
\hline & 207302 & 17104 \\
\hline 12 & $(230700)$ & - \\
\hline & 791940 & $(55$ 991) \\
\hline 5 & $(526320)$ & (335 955) \\
\hline & $£ 265620$ & $(£ 391946)$ \\
\hline
\end{tabular}

General administrative expenses

Investment and exchange net gains

Provision for pensions of certain retired members of staff .

Surplus (1980—deficit) before taxation

$\begin{array}{llll} & \cdots & & \end{array} \quad$.

Taxation ..

Surplus (1980-deficit) after taxation ..

The notes on pages 29 and 30 form part of these accounts. 


\section{British Medical Association}

Balance Sheet-31 December 1981

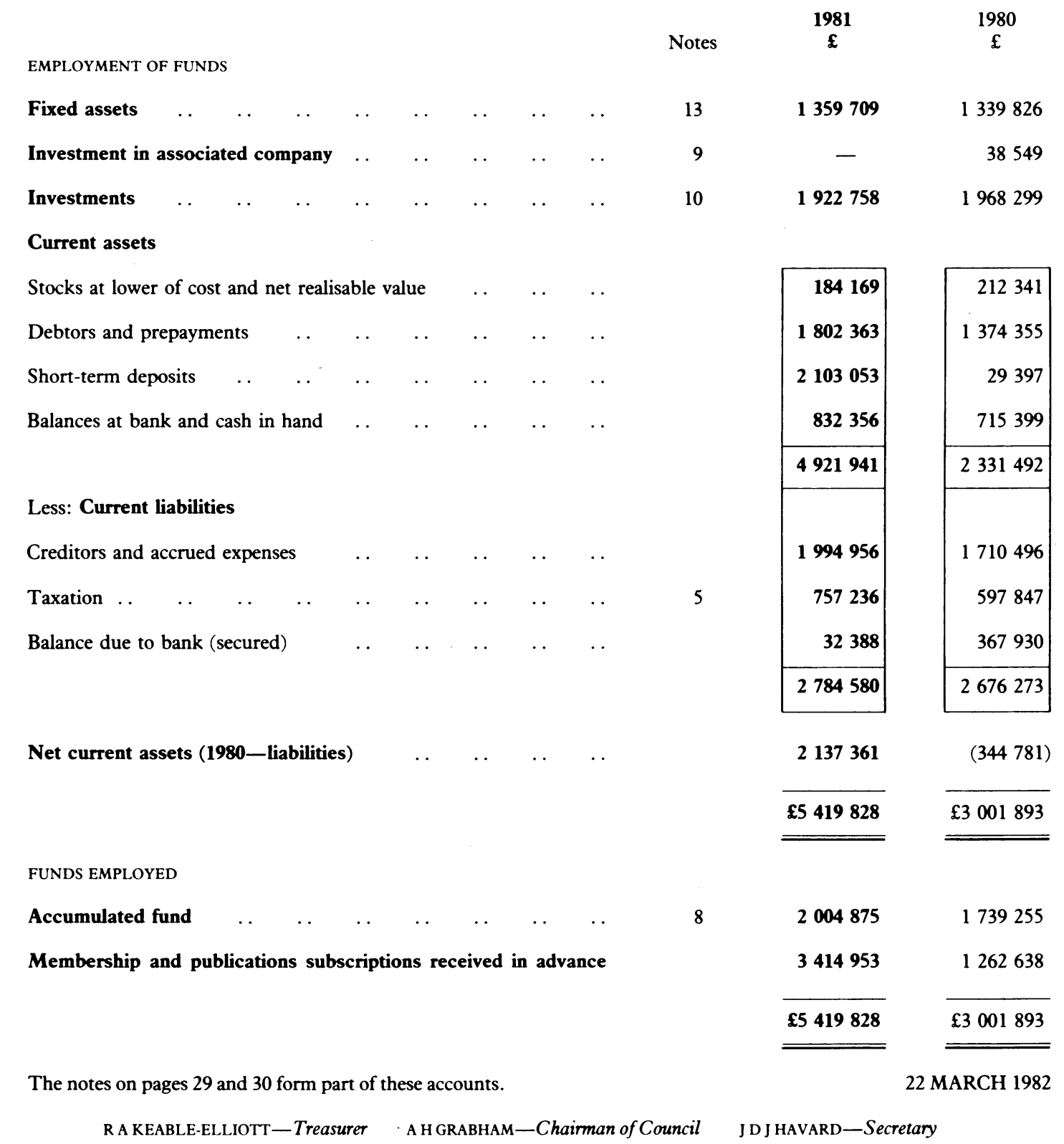

AUDITORS' REPORT TO THE MEMBERS OF THE BRITISH MEDICAL ASSOCIATION

We have audited the financial statements included in Appendix IV on pages 26 to 30 in accordance with approved Auditing Standards.

In our opinion the financial statements, which have been prepared under the historical cost convention as modified by the revaluation of freehold properties, give under that convention a true and fair view of the state of the Association's affairs at 31 December 1981 and of its surplus and source and application of funds for the year then ended and comply with the Companies Acts 1948 to 1981 .

Southwark Towers

32 London Bridge Street

PRICE WATERHOUSE

London SE1 9SY

Chartered Accountants 


\section{British Medical Association}

\section{Statement of source and application of funds for the year ended 31 December 1981}

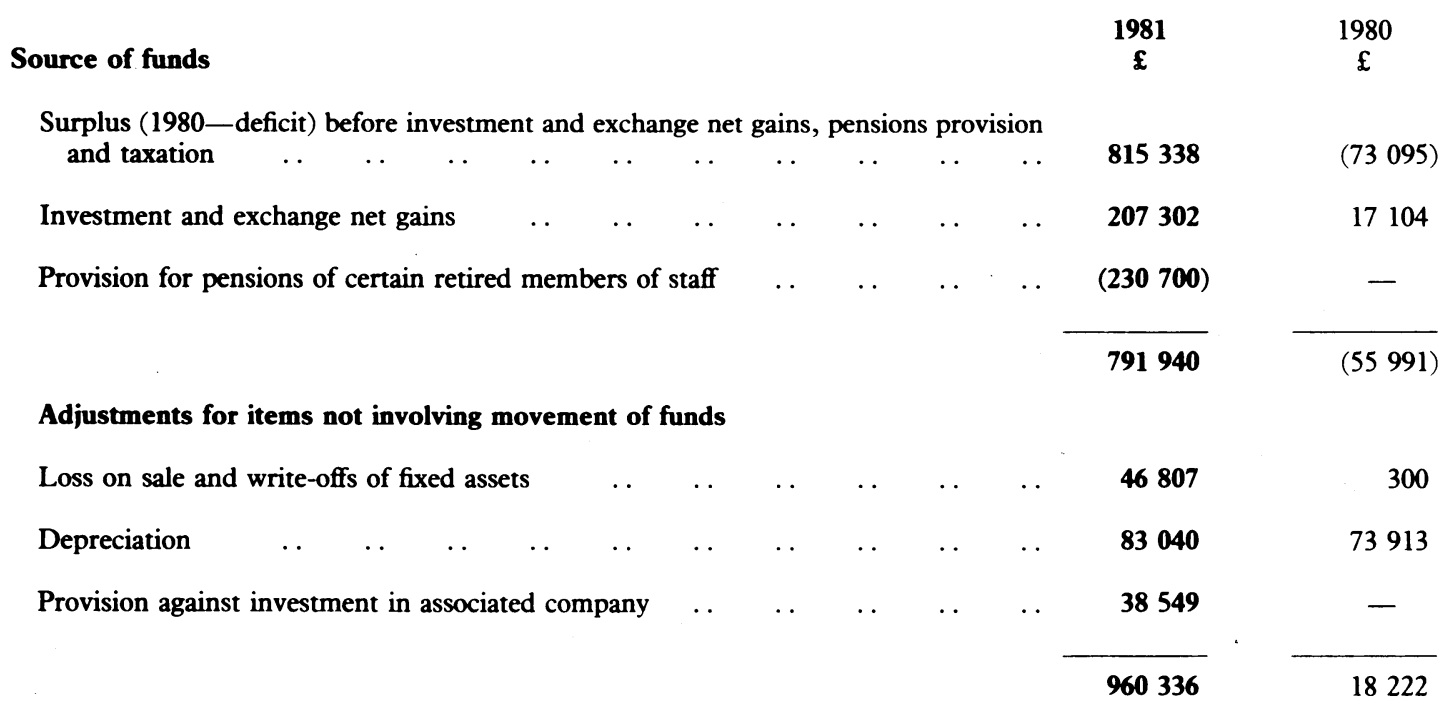

Funds from other sources

$\begin{array}{lllllllllll}\text { Proceeds of sale of fixed assets } & \ldots & \ldots & \ldots & \ldots & \ldots & \ldots & \ldots & \ldots & 4185\end{array}$

Net sale of investments

\section{Application of funds}

Purchase of fixed assets

Increase in membership and publications subscriptions received in advance ..

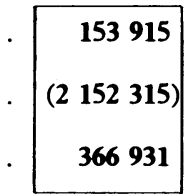

\section{Represented by:}

Increase (1980-decrease) in working capital

Decrease in stocks .

Increase in debtors and prepayments

Increase in creditors and accrued expenses

Movement in net liquid funds

Increase in short-term deposit, bank and cash balances 


\section{British Medical Association}

\section{Notes to the Accounts for the year ended 31 December 1981}

1 The Association is a company limited by guarantee, the liability of members being limited to one guinea each.

\section{Accounting policies}

\section{(a) PUBLICATIONS}

Income and expenditure relating to publications is accounted for in the year within which the date of the publication falls. Income from subscriptions is deemed to accrue evenly over the period of the subscriptions; the proportion of subscriptions invoiced but unearned at the balance sheet date is deferred.

\section{(b) MEMBERSHIP SUBSCRIPTIONS}

Membership subscriptions are taken into income in the year to which they relate. Amounts received by the balance sheet date in respect of future years are deferred.

\section{(c) DEFERRED TAX}

Provision is made for any deferred tax, calculated on the liability method, unless it can be demonstrated that it will not require to be paid in the foreseeable future.

\section{(d) FOREIGN EXCHANGE}

The Association maintains certain bank and debtor accounts in foreign currencies. These accounts have been converted at the mid-market rate ruling at the year end Exchange gains and losses arising during the year are dealt with in the Income and Expenditure Account.

\section{(e) FIXED ASSETS}

Renewals to furniture, fittings, and library books are charged direct to revenue in the year of purchase and in 1981 amounted to $\$ 6850$ (1980—£13 742). Depreciation on fixed assets other than cars is charged on cost or valuation on a straight line basis at rates estimated to write them off over their useful lives. Cars are depreciated on a reducing balance basis.

\section{Income from investments and deposits}

Government and other listed investments Short-term investments and deposits

\begin{tabular}{|c|c|}
\hline $\begin{array}{c}1981 \\
\mathcal{E} \\
271645 \\
50703\end{array}$ & $\begin{array}{c}1980 \\
\mathcal{L} \\
227523 \\
35180\end{array}$ \\
\hline$£ 322348$ & $£ 262703$ \\
\hline
\end{tabular}

\section{Net surplus on publications}

Turnover:

Sale of copies

Advertisements

Sundry receipts (reprints, etc)

Deduct: Publications expenditure .

\begin{tabular}{|c|c|}
\hline \begin{tabular}{ccc} 
& \multicolumn{1}{c}{1981} \\
& \multicolumn{1}{c}{${ }^{2}$} \\
2 & 137 & 187 \\
4 & 185 & 554 \\
& 600 & 559
\end{tabular} & \begin{tabular}{cc} 
& 1980 \\
& \multicolumn{1}{c}{} \\
1 & 803453 \\
3 & 324515 \\
510321
\end{tabular} \\
\hline $\begin{array}{l}6923300 \\
6708231\end{array}$ & $\begin{array}{l}5638289 \\
5613383\end{array}$ \\
\hline$£ 215069$ & $£ 24906$ \\
\hline
\end{tabular}

\section{Taxation}

Taxation based on the surplus for the year at $52 \%$ (1980-52\%):

UK corporation tax

Deferred tax

Taxation suffered on franked investment income received

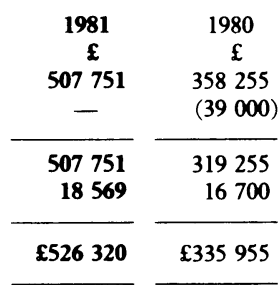

U.K. taxation is based on the surplus for the year arising on income from properties, investments and exchange gains, and the surplus on publications. The charge is analysed as follows:

\begin{tabular}{|c|c|c|c|c|c|}
\hline \multirow{4}{*}{$\begin{array}{l}\text { Properties } . . \\
\text { Investments and exchange } \\
\text { Publications ... }\end{array}$} & \multirow{4}{*}{$\begin{array}{l}\cdots \\
\cdots \\
\cdots\end{array}$} & \multirow{4}{*}{$\begin{array}{l}\cdots \\
\cdots \\
\cdots\end{array}$} & \multirow{4}{*}{$\begin{array}{l}\cdots \\
\cdots \\
\cdots\end{array}$} & \multirow{4}{*}{$\begin{array}{c}1981 \\
\text { E } \\
241 \\
1921 \\
198922 \\
86077\end{array}$} & \multirow{4}{*}{$\begin{array}{c}1980 \\
£ \\
222850 \\
149917 \\
(36812)\end{array}$} \\
\hline & & & & & \\
\hline & & & & & \\
\hline & & & & & \\
\hline & & & & $£ 526320$ & $£ 335955$ \\
\hline
\end{tabular}

$£ 448593$ (1980—£309 700) of the corporation tax liability is payable on 1 January 1983.
6 Expenditure on premises occupied by Association departments is allocated in proportion to space occupied and is included in publications expenditure (note 4) and in the various expense headings referred to in the Income and Expenditure Account; the balance of expenses on premises of $£ 388430$ (1980 — $£ 298710$ ) not recovered in this way is regarded as applicable to tenanted accommodation and is included under Finance and Estates.

7 Finance and Estates charges include auditors' remuneration of $£ 16757$ (1980$£ 14448$ ), of which $£ 1757(1980-£ 1198)$ is in respect of prior years, and overdraft interest $£ 14743(1980 \ldots £ 29719)$.

\section{Accumulated Fund}

Included in this fund are amounts set aside for the development of computer activities $£ 43304(1980$-£120409).

\section{Investment in associated company}

The Association owns $50 \%$ of the ordinary share capital of Tavistock Computer Services Limited, a company registered in England. The cost of this investment has been fully provided in the current year since the original cost related principally to computer software which is no longer in use. Expenditure on new computer software is written off as incurred.

\section{Investments}

Government and other investments listed in UK at cost

Investments listed overseas at cost $\quad \ldots \quad$.

\begin{tabular}{|c|c|}
\hline $\begin{array}{c}1981 \\
£ \\
1669725 \\
253033\end{array}$ & $\begin{array}{c}1980 \\
\mathcal{E} \\
1746992 \\
221307\end{array}$ \\
\hline & $£ 19$ \\
\hline
\end{tabular}

(Market value $£ 2019142 ; 1980-£ 2212812$ )

11 (a) The emoluments paid or payable in 1981 to the Chief Officers of the Association and to chairmen of certain major committees amounted to $£ 16623$ (1980- $\$ 35464$ ).

11 (b) The number of employees whose remuneration, excluding pension contributions, exceeded $£ 20000$ was as follows:

$£ 20001-£ 25000$
$£ 25001-£ 30000$
$£ 30001-£ 35000$

$\begin{array}{cc}1981 & 1980 \\ 8 & 6 \\ 3 & 1 \\ 2 & 1\end{array}$

\section{Pensions}

The triennial valuation of the Staff Pension Scheme carried out by the actuaries as at 31 March 1979, prepared by discounting the expected future income and outgoings of the Scheme, showed an excess of assets over liabilities of $\$ 486000$. Council decided to accept the recommendations of the actuaries in applying this excess as follows:

(i) With effect from 1 January 1980 the trustees of the Staff Pension Scheme assumed responsibility for the payment of pension increases awarded between 1 April 1974 and 31 December 1978.

(ii) The Association reduced the rate of its annual contribution for the year ending 31 December 1980 by $£ 57000$ being $2 \frac{1}{2} \%$ of staff salaries eligible for pension purposes. With effect from 1 January 1981 the rate has been restored to that applying at 31 December 1979 .

The cost of pension increases awarded since 1978 and any future pension increases which may be awarded by the Ascociation in respect of pensioners within the Scheme will continue to be borne by the Association as incurred. In recent years pensions have will continue to be borne by the Association as incurred. In recent years pensions have
been increased to take account of inflation. The amount paid in 1981 in respect of pension increases awarded from 1979 to 1981 was $£ 74547$ (1980-£31666). The actuarially calculated assessment of the liability of the Association at 31 December 1981 in respect of these 1979 to 1981 increases, using a discount rate of $14 \%$, was approximately $£ 555000(1980-£ 431500)$, for which no provision has been made in the mately $£ 555000(1980-£ 431500$ ), for which no provision has been made in the
accounts. With advice from the actuaries the trustees of the Staff Pension Scheme may authorise a contribution to the cost of these and any future pension increases from actuarial surpluses of funds, if any, which may arise from time to time. The next actuarial valuation of the Staff Pension Scheme will take place as at 31 March 1982.

The Association also pays pensions from its own resources to certain retired members of staff, many of whom retired prior to the introduction of the current pension scheme on 1 April 1974. The amount of these pensions paid by the Association in 1981 was f87870 (1980 - 661593$)$. It is intended that the Staff Pension Scheme will assume responsibility for the pensions of certain of these retired members of staff in 1982 for which the actuaries have calculated that a sum of $£ 230700$ should be paid over to the scheme by the Association which includes an amount for expected future inflationary rises in the pensions concerned. This amount has been charged in the accounts. The actuarially calculated assessment of the liability of the Association at 31 December 1981 in respect of those pensions not covered by the amount of $£ 230700$ referred to-above using a discount rate of $14 \%$, was approximately $£ 375000$, for which no provision has been made in the accounts. At 31 December 1980 the actuarially calculated assessment of the liability of the Association for all pensions paid from its own resources, using a discount rate of $14 \%$, was $£ 449500$. No provision for this was made in the accounts. 


\section{British Medical Association}

Notes to the Accounts for the year ended 31 December 1981 (continued)

13 Fixed assets

$\begin{array}{cccc} & \text { Freehold } & \text { Office } & \text { Moto } \\ \text { Total } & \text { premises } & \text { equipment } & \text { cars }\end{array}$

⿷

$£$

$£$

Cost or valuation -1 January 1981

1861378

1384317

341086

Additions during year

Disposals and amounts written off during year

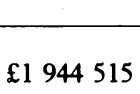

\section{$£ 1458097$}

Cost or valuation-31 December 1981
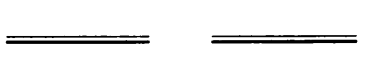

$£ 348851$

$£ 137567$

Less:

Accumulated depreciation-1 January 1981

521552

306200

156628

58724

Charged in year ..

83040

17177

39196

Disposals during year

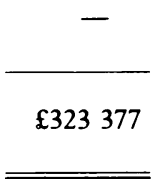

(6 592)

(13 194)
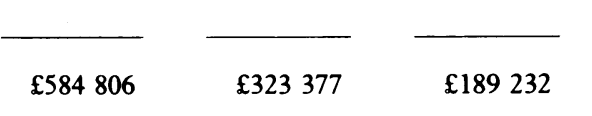

$£ 72197$

Accumulated depreciation-31 December 1981

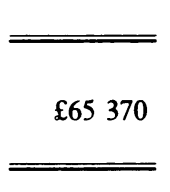

Depreciation rates

See note $(a)$

$10 \%$

$25 \%$

(a) Freehold premises are included at a 1957 professional valuation of $\$ 800000$ with the exception of those held by feu charter which are at net book amount on 1 January 1947. All additions since have been at cost. Depreciation of $£ 11696$ has been provided for Tavistock House and the remaining premises are being written off over 50 years.

(b) Office equipment includes an initial stock of audiovisual training material. Furniture and fittings $(£ 20000)$ and library books $(£ 27000)$ have been written off in 1981. The initial stock of audiovisual training material amounts to $£ 44000$ and is being amortised over a maximum period of four years. Office equipment and motor cars are stated at cost.

\section{Appendix V: Budget for 1982 (unaudited)}

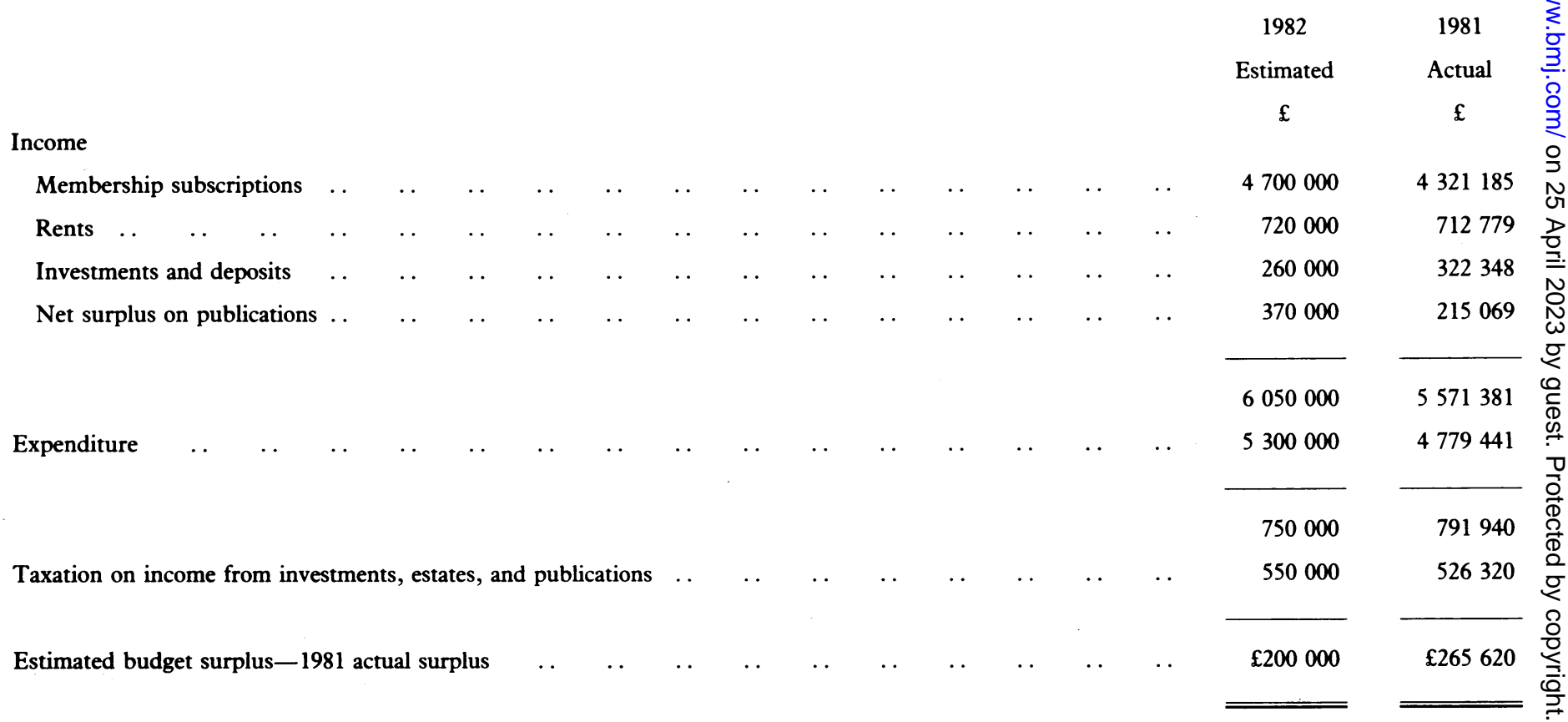


Appendix III-continued from $p 25$

priate it should be replaced by a consultant post.

\section{Recommendation 11}

In 1979 the Council approved recommendation $\mathrm{H}$ of the Wilson Working Party Report that discussions take place between the professions, the universities, and the Health Departments to ensure that honorary NHS contracts are granted with the approval of a Central Manpower Committee for England and Wales. The Association can support recommendation 11 with the important rider that, if implemented, it is recognised that those in research posts may require honorary contracts to allow them access to patients. Some academic posts have been created because they are a requirement of the medical school teaching load. This teaching load does not necessarily match up with NHS manpower requirements but is, nevertheless, vital to the satisfactory teaching of medical students and the maintenance of academic standards.

\section{Recommendation 12}

The Council agrees that better manpower data systems are needed at regional level. It also supports the recommendation because of the importance it attaches to the fostering of good relationships between postgraduate deans and community physicians to permit co-ordination of training and staffing.

\section{Recommendation 13}

The Council supports this recommendation.

\section{Recommendation 14}

The HJSC supports a freeze at SHO level of the total number of SHO posts. Para 230 of the Short Report states:

"As we have seen over the past decade health authorities have been creating additional SHO posts with very little difficulty. There is evidence that some regional manpower committees are beginning to look more carefully at bids for SHO posts:

" "The DHSS) did raise, in the Chief Medical Officer's letter, the possibility of a voluntary freeze on the creation of further SHO posts. Most of the regions where we have discussed this, are perfectly willing to look at it and in fact some regions have already implemented an SHO freeze." "

This, however, is a very new departure and it could take years before all health authorities followed suit. If planned training is to be introduced and the number of consultants increased, we see absolutely no reason for allowing the present chaotic trend to drift on, uncontrolled, as it has been.

The CCHMS does not favour a standstill because of the implications for the employment prospects of junior staff and the effect on the care of patients. Nevertheless, the CCHMS has been urging a controlled SHO grade. The HJSC believes that SHO contracts should be held at regional level and thus it would be possible to develop a mechanism for redistributing SHO posts between specialties. Clearly the matter will be greatly influenced by the Secretary of State's decision on the siting of SHO contracts but it seems obvious that firm control of the grade might best be achieved through the machinery of the Central Manpower Committee.

\section{Recommendation 15}

The Council supports this recommendation.

\section{Recommendation 16}

The Council accepts that hospital patients should be treated personally by consultants or by juniors under the control of a consultant. It is obviously not practicable for juniors always to be under the direct control of a consultant (as advocated by the Short Committee) in carrying out every procedure but both sides are agreed that control should be adequate and appropriate.

\section{Recommendation 17}

The Council does not support this recommendation believing its proposals to be too rigid. The matter is complex and needs to be carefully planned.

\section{Recommendation 18}

The Council accepts the terms of the recommendation.

\section{Recommendation 19}

The Council supports this recommendation but it believes that the emphasis must be on ensuring that where possible adequate training is given in all hospitals which provide emergency services. This will allow a fair distribution of junior staff and will not place consultants who work in peripheral hospitals at a disadvantage.

\section{Recommendation 20}

The Council believes that this idea is a good one in principle-although it might be very difficult to implement-but the members of the Council cannot agree that it should be compulsory for postregistration trainees to spend periods of up to a year in other specialties. The royal colleges and faculties should continue to recognise time spent training in another specialty.

\section{Recommendation 21}

The Council supports this recommendation, provided that the facilities for training are available in the hospitals selected. While recognising the value of a planned programme it should not preclude movement between regions.

\section{Recommendation 22}

The Council rejects this recommendation chiefly because this kind of shortened programme would lead to difficulty in maintaining standards. It is for individual royal colleges and faculties to determine the length of their own training programmes.

\section{Recommendation 23}

The Council accepts this recommendation. It is current practice.

\section{Recommendation 24}

The Council can support this recommendation provided that with any improved information and monitoring system there were adequate means of protecting the confidential data on doctors stored in the systems. Career guidance to doctors in training is a matter which the Association has reviewed carefully over the past few years. Career advice would appear to fall into two main divisions.

(i) Advice given by the individual consultant or GP trainer to the individual trainee on his performance, progress, and prospects in that particular specialty.

(ii) General advice on career prospects and job availability and content in all specialties.

The latter would appear to be the appropriate function for postgraduate deans and clinical tutors.

\section{Recommendation 25}

The Council supports this recommendation.

\section{Recommendation 26}

That there should be some career guidance for all junior doctors has been agreed in the JCC, whose view has been submitted to DHSS. Recommendation $F$ of the Wilson Working Party's Report, which was not approved by the Council, called for the introduction of training programmes of limited tenure for doctors from overseas. In the case of overseas doctors it must be accepted that career guidance is primarily a function of the royal colleges.

\section{Recommendation 27}

Resolution 38 was approved at the ARM 1981 as follows:

"That this Representative Body deplores the fact that no action has yet been taken on the matter of the continued working of the one-in-two rota for junior hospital doctors and continues to believe that excessive work load puts patients' lives in jeopardy."

Senior hospital doctors already accept the terms and conditions of service for hospital junior staff as follows:

"It is recommended that, in the assessment of contracts a minimum of 88 hours per week of assured period of off duty, including freedom from on-call liability, should be made available to practitioners, always provided that the needs of patients permit."

Therefore, if their recommended minimum off-duty time is 88 hours a week, their contracted week should consist of 80 hours.

The Council believes that the 88-hour minimum off-duty time should be implemented in the terms of the existing agreement rather than enforced, as suggested, in recommendation 27.

While the hospital junior staff would like to see this implementation carried out speedily, senior hospital staff believe that there may be serious problems in some hospitals and specialties if this were to be done too hastily and in particular the CCHMS has the gravest 
reservations about the practicabilities of introducing shift work. There is general agreement that there should be adequate financing of the hospital service to avoid exploitation of hospital junior staff by health authorities unwilling to pay for locum cover.

\section{Recommendation 28}

This complicated matter requires more detailed careful study.

\section{Recommendation 29}

The proposals in recommendation 29 have been overtaken by events and there is no need to comment upon them here.

\section{Recommendation 30}

The Council supports this recommendation. The HJSC representatives considered this to be most important as region is where the planning of training will occur. The CCHMS representatives agreed that senior registrar and registrar contracts should be held at regions.

\section{Recommendation 31}

The Council supports this recommendation.

\section{Recommendations 32 and 33}

Council policy is as in the Manpower Working Party recommendation A which demands that a body be established to keep under continuous review medical manpower, staffing, and training requirements in Great Britain. There is an undoubted need for such a body but the GMC may not be the most appropriate organisation to undertake this function. It has a majority of members elected by the medical profession and it is responsible for setting and maintaining standards of professional conduct and throughout the range of medical education. It is quite inappropriate for the GMC to be formally linked with the Health Departments whose prime object must be the efficient and economical management of the NHS. Council, therefore, strongly rejects recommendations 32 and 33, and 34 which is consequent upon them. Chapter 6 of the Short Report which produced recommendations 32 and 33 was strongly criticised.

\section{Appendix VI: Amendments to the Articles, Bylaws, and Schedules to the Bylaws}

\section{Amendment of Articles}

Article 9: Delete the last sentence.

Article 14(a): Delete "in such manner as the Council may prescribe" and substitute "by the Central Ethical Committee."

Line 14. Delete "under paragraph (d) of the last preceding Article" and substitute "on the ground that his conduct has been detrimental to the honour and interests of the medical profession or the Association or calculated to bring the profession into disrepute or that he has wilfully and persistently refused to comply with the Articles or the Rules of any Division or Branch of which he may be a member, Overseas Associate or Associate Member (as the case may be)."

Insert the following after Article 47:

"Secretary

47A. The Secretary shall be appointed and may only be dismissed by the Council, and shall hold office for such period and perform such duties and receive such remuneration as the Council may from time to time determine. Before appointing the Secretary, the Council shall advertise the post publicly in such manner as the Council may from time to time determine."

\section{Amendment of Bylaws}

Bylaw 18 (1): Delete subparagraph (b).
Bylaw 37: Delete in entirety and substitute: "It shall be the duty of the Council to define the Constituencies for the purposes of electing representatives of the Divisions and the Council shall from time to time publish lists of the Constituencies, showing the Divisions comprised in each and the number of representatives each is entitled to elect and of the Divisions for the time being entitled to elect further representatives under paragraph (3) of Bylaw 38."

Bylaw 38: Delete subparagraph (4) in its entirety.

Bylaw 39: Delete subparagraph (2) in its entirety and renumber the subsequent subparagraphs.

Subparagraph (9): In line 2, delete "paragraphs (1) and (2)" and substitute "paragraph (1)" and, in line 7, delete the words "follow the procedure laid down in the said paragraphs (1) and (2)" and substitute "be amended in such manner as the Council shall prescribe."

Subparagraph (10): Delete the first two lines and line 3 to the word "representative" and substitute "The Secretary of every Division."

Bylaw 40 (5): In the second line, delete "(3)" and substitute "(2)."

Bylaw 47: In paragraph (1) line 8, insert the word "Medical" before the word "Academic."

Bylaw 66: Delete paragraph (2) in its entirety.
Bylaw 67: Delete the last sentence.

(Provision is already made in Article 44(i) for the Chairman of Council and the Treasurer to be ex-officio members of the Council while holding office and for one year after their ceasing to hold office.)

Bylaw 71: Delete in its entirety and renumber subsequent Bylaws.

Bylaw 76: Delete in its entirety and renumber subsequent Bylaws.

\section{First Schedule to the Bylaws}

Column 6, lines 10-12: Delete the words "the Department of Audio Visual Communication, the Film Library" and insert "the British Life Assurance Trust."

\section{Second Schedule to the Bylaws}

Central Ethical Committee. Column 6: Delete: "paragraph (d) of Article 13" and substitute "Article 14 (a)."

Central Committee for Community Medicine. Column 2: Delete "(without voting rights)."

Medical Academic Staff. Column 6: Insert at the end "The committee shall have power to co-opt up to three members in order to secure the representation of all groups of full-time medical academic staff." 